\title{
Managed Floats to Damp World-Wide Exchange Rate Liquidity Shocks Like 1982-5, 2006-9: Field and Laboratory Evidence for the Benefits of a Single World Currency
}

\author{
Robin Pope ${ }^{*}, 1$ and Reinhard Selten ${ }^{2}$ \\ ${ }^{I}$ Experimental Economics Laboratory and Center for European Integration Studies (ZEIb), Bonn University, Walter Flex Str \\ 3, ZEIb, D-53113 Bonn, Germany \\ ${ }^{2}$ Experimental Economics Laboratory, Bonn University, Germany
}

\begin{abstract}
This paper's field evidence is: (1) in reality a major exchange rate change devastates an economy, i.e. the widespread academic faith that exchange rate changes are either beneficial or harmless is a false faith that contributes to needless world-wide economic havoc; (2) the 1982-85 exchange rate liquidity crisis sent much of the third world into unmanageable debt levels and was so devastating for the first world that in 1985 the G5 instituted managed cooperating floats; (3) nearly all economists in the official sector and in academe rapidly forgot the devastation and reverted to advocating what caused that devastation, namely a closed economy clean floats exchange rate perspective; and (4) the 2006-2008/9 exchange rate liquidity shock would have been far more drastic but for central bank currency swaps yet the role of these swaps in averting unmanageable exchange rate mayhem that would have precluded the September 2008 rescue of the world financial system, has been ignored. The field evidence thus decisively favours stabilizing managed floats, or better a single world currency, and a means of preventing economists in official sectors and in academe forgetting the devastation and dangers of multiple currencies.

This field evidence is bolstered by a laboratory experiment. The experiment incorporates more aspects of real world complexity and more different sorts of official and private sector agents than other investigations and employs a new central bank cooperation-conflict model of exchange rate determination. The experiment allows an interpretation within an umbrella theory of Pope, namely SKAT, the Stages of Knowledge Ahead Theory.

Our joint field plus laboratory evidence indicates that official sectors should maintain an international exchange rate oriented perspective as advocated in Davidson 2009 and in the September 2010 Report by UNCTAD, the UN Conference on Trade and Development. But our field evidence details needless fragility in cooperatively managed exchange rate systems. Our joint field plus laboratory evidence thus favours a single world currency, a possibility put on the agenda in March 2009 by Zhou Xiaochuan, head of the People's Bank of China, recommended in July 2009 by the Russian President Dmitry Medvedev, and forwarded as an option in the April 2010 International Monetary Fund Report on Reserve Accumulation and International Monetary Stability.

To avoid rapid forgetting of havoc from isolationist clean floats and the value of stable exchange rates, indeed better yet a single world currency, a new syllabus, as under the SKAT umbrella, is fundamental. SKAT allows for risk effects including those from (a) difficulties of agents in evaluating alternatives in a complex environment in which the assumed maximization of expected utility is impossible; (b) planning difficulties under uncertainty; and c) the preference for safety and reliability is not trivialized. SKAT contrasts with the current economists' paradigm of expected utility and game theory that lacks a), b) and c) and hence lacks a means for economists to understand that exchange rate uncertainty matters. SKAT is fundamental for the education of official sector members in order to furnish them with a coherent alternative intellectual framework to current university education that excludes liquidity crises and debt costs due to unpredicted exchange rate changes.
\end{abstract}

JEL Classification: D80, F31.

Keywords: Managed float, IMF, exchange rate regime, experiment, SKAT the stages of knowledge ahead theory, exchange rate shocks, central bank cooperation, central bank conflict, UNCTAD, learning, forgetting, maximizing, expected utility theory.

\section{INTRODUCTION}

\subsection{An Exchange Rate Liquidity Shock}

Major unpredicted relative price changes in two currencies is a definition of an exchange rate liquidity shock,

*Address correspondence to this author at the Experimental Economics Laboratory and Center for European Integration Studies (ZEIb), Bonn University, Walter Flex Str 3, ZEIb, D-53113 Bonn, Germany; Tel: +49228-731887, +49-228-4462880, +49-151 124070 1; Fax +49-228-4462881; E-mail: Robin.Pope@uni-bonn.de especially when preceded or accompanied by a major unpredicted rise in the cost of borrowing in either currency. The word unpredicted here means that. It does not mean an event that agents probabilistically anticipated. It thus means that, if agents were previously in anything that might be described as an equilibrium in the sense of getting the consequences of their actions that they anticipated, this is no longer the case. It means the chaos of agents dealing with the unanticipated. The term exchange rate liquidity shock is thus here used to mean, in so far as the notion of the 
complementary alternative situation of an equilibrium is meaningful, that all markets significantly affected by exchange rates are in a disequilibrium.

The exchange rate changes in the post Bretton Woods era have not been systematically probabilistically predicted by by academic economists, official sectors or firms, parts 3 and 4 below. They have been unpredicted. Therefore essentially any change of the exchange rate can be treated as unpredicted. This paper will however for brevity concentrate on the massive exchange rate liquidity shocks endured world-wide since the demise of Bretton Woods.

\subsection{Faith that Exchange Rate Liquidity Shocks are Beneficial}

There is a widespread faith amongst academic economists that although the causes of banking crises are disequilibrium behaviour, any associated exchange rate liquidity shocks are equilibratingly beneficial, e.g. $[1, \text { p28 }]^{1}$ and [2]. But after 40 years of econometric effort, the fundamentals of supply-demand equilibration from exchange rate changes have never been discerned. It is seriously misleading and ethically dubious, when multiple currencies are a choice advised by economists, to describe agents thrown into chaos by exchange rate liquidity shocks as being "shifted in equilibrium". The term equilibrium misleadingly connotes that economists have discovered fundamentals that imply that these exchange rate liquidity shocks, somehow counter-intuitively, improve the market and economic planning. This faith without discovery of any supporting evidence in equilibrating exchange rates is exceedingly widespread and influential on policy. Accordingly sections 3 and 4 below detail what economists have not discovered.

\subsection{Belief that Exchange Rate Changes are Harmless}

Some embracing the faith that exchange rate changes are equilibrating have attempted to deal with the obvious question, does not commonsense tell us that any unanticipated exchange rate damages the economy. One answer is to argue that there is no significant damage since even after massive unpredicted exchange rate liquidity shocks, the aggregate consumer price index changes little, e.g. $[3]^{2}$. But the aggregate consumer price index comprises primarily non-traded items and hides the damage suffered by subgroups such as importers and ignores entirely international borrowers and real debt.

Another answer is to argue that if the resultant decline in aggregate trade is measured by short-term exchange rate volatility (often as short as a week, never beyond a year), little decline is detected. ${ }^{3}$ The empirical evidence is that after

\footnotetext{
${ }^{1}$ Australia is a commodities exporter. Its official sector enables wild exchange rate swings. These generally mimic, though not in at all a predictable manner within the two year time horizon, the wild swings in prices to which commodities are subject. Reinhart and Rogoff [1, p28] praise Australia's official sector for allowing the Australian dollar to swing wildly.

${ }^{2}$ Since the purchasing power parity theory of exchange rates is false, a massive exchange rate change translates into a far smaller change in consumer price index.

${ }^{3}$ Cross sectional studies of trade inside and outside currency unions, indicate substantial damage from exchange rate liquidity shocks, e.g. [8].
}

an exchange rate change, manufacturing firms rarely engage in the major matter of altering fixed investments for advertising and distribution in foreign countries and the associated trade flows in less than 18 months [4-7]. In summary, traded items are not created overnight like hot money contracts, inferences from such econometric estimates of exchange rate changes generating at most minimal trade reductions, stem from an irrelevant misapplication to real sector trade of financial asset theory for hot money flows.

As can be seen from sections 1d), 1e) and 1f) below, when damage from exchange rate liquidity shocks is appropriately measured and considered for relevant subgroups, it is drastic.

\subsection{Import Competing Sectors Shriveled or Obliterated by Depreciations}

For avoiding missing damage from exchange rate changes, sectoral decomposition is fundamental. Aggregate approaches, when combined with other misspecifications, routinely yield the false conclusion of zero harm since they conflate sectors benefitting from a depreciation, e.g. exporters, and those hurting. Those hurt by a depreciation are likely to be the import-competing manufacturing sector of a country, as an input-ouput decomposition reveals that this sector is the principal user of imports and exportables [9]. The estimate for Australia is that a depreciation contracts this sector by $40 \%$ of the percentage of the exchange rate depreciation [4-7,10].

For the entire OECD, the corresponding estimate of this contraction is lower, $20 \%$ [11, chapter 1]. However since Sheet's estimation period included the early to mid $1980 \mathrm{~s}$ when the exchange rates of most OECD members depreciated about $100 \%$ against the USD, this meant a $20 \%$ drop in the output of their import competing sectors, a magnitude no policy maker ought take as trivial. Further the drop in profits of the import competing manufacturing sectors in OECD countries was even more drastic, $70 \%$, with investment also very significantly damaged $[11$, chapter 1$] .{ }^{4}$

It is small wonder that in some of these OECD countries, the import competing manufacturing sector was so weakened by these exchange rate liquidity shocks, that it was unable to adjust to other pressures, and in less than a decade was essentially extinct.

\subsection{International Borrowers Damaged or Bankrupted by Unanticipated Depreciations}

Most international debt is USD denominated with much infeasible to hedge. Every exchange rate liquidity shock yields an arbitrary redistribution of international real wealth in the trillions, patently unjust and economically grossly inefficient. For non-US borrowers whenever this shock is a rise in the US dollar there has been a causally related unpredicted sharp rise in world interest rates. Interest repayments due to international creditors thus have

\footnotetext{
${ }^{4} \mathrm{~A}$ like set of comments relate to the comparable damage done to the import-competing sector of the US between 1985 and 1987 over which time, essentially the USD roughly depreciated $100 \%$.
} 
unpredictably risen far in excess of the unpredicted massive rise in the value of the USD relative to other currencies. But the international financial system does not remain viable enough for all borrowers to roll over their loans as planned (albeit at the new higher interest rates). Many borrowers face the even more drastic situation of having to repay at once the principal or to declare bankruptcy. The upshot is bankruptcies of massive long-standing international firms e.g. Pasminco, and episodic extreme losses of central banks e.g. the UK one, and of treasuries, e.g. the Australian one.

\subsection{Domestic Borrowers Damaged by Exchange Rate Changes}

Official sectors such as those in Australia and New Zealand allow their currencies to swing wildly compared to major bloc currencies. This choice imposes exchange rate risk premia on their international borrowings and these risk premia filter through to domestic borrowers who borrow from commercial and investment banks that partially raised their funds overseas. In the case of Australia and New Zealand domestic interest rates, depending on which interest rate is used in which span of years, is between 4 and 10 times higher than that of other first world countries that pursue more stable exchange rates on a trade or trade and capital weighted basis. This massive interest surcharge is an avoidable heavy burden on investment in such countries.

\subsection{Damage Summary}

Taking into account the welfare of 1) the traded sector, 2) international borrowers, and 3) domestic borrowers, it becomes apparent that exchange rate liquidity shocks are devastating to at least one of the pair of countries, and often to both of them. This paper accordingly investigates which exchange rate regime minimizes the magnitude and likelihood of the devastation of exchange rate liquidity shocks.

\subsection{World-Wide Exchange Rate Liquidity Shocks}

Since 1970 there have been two: (i) the doubling and then reversion in the USD and in world interest rates in the 1980s; and (ii) the steep rise in the USD and interest rate spreads between 2006 and 2008/9. Three other potential world-wide exchange rate liquidity shocks were, from the viewpoint of most first world countries, damped or averted due to swift action by Alan Greenspan and the US Federal Reserve Board, namely those arising from: (iii) Long Term Capital Management's 1998 mispredictions of the liquidity of some bonds, stocks and currencies; and (iv) the bursting of the dotcom bubble that precluded some foreign firms raising funds for US direct investment in the US and other foreign firms from being able to roll-over their US denominated debts; and (v) the September 11, 2001 attack on the US which created an abrupt drop in demand for USD. A few first world countries (par excellence Australia and New Zealand), and many emerging and developing countries, have experienced considerably more than two exchange rate liquidity shocks since 1970 .

\subsection{Paper's Goal}

This paper investigates which exchange rate regime caused the two actual world-wide exchange rate liquidity shocks that have occurred. It concomitantly investigates which exchange rate regime damped or averted the other three potential world-wide exchange rate liquidity shocks.

For economics to be a science, attention to history, to what actually happened, is required. Most economists who experienced it, quickly forgot the devastation of the 19821985 exchange rate liquidity shock, and neither the media nor academe alerted economists adequately to why the potential and actual subsequent exchange rate liquidity shocks were damped or averted. The paper therefore includes historical material on what actually happened, that is includes material on what economics as a science needs to recognize and explain with respect to exchange rate liquidity shocks.

\subsection{Exchange Rates: Regimes and Understanding of why they Change}

The paper uses a 3-way division of exchange rate regimes: 1) clean floats believed by their advocates to maintain equilibrium; 2) dirty floats believed by their advocates to speed return to equilibrium after specific shocks; and 3) managed floats believed by their advocates to stabilize exchange rates. Part 2 delineates these three regimes. Parts 3 and 4 analyse economists' failure to discern the equilibrating fundamentals assumed by those advocating both the clean and dirty float regimes, and our minimal progress via current econometric estimates in understanding why exchange rates change, and virtually zero success in predicting these changes.

\subsection{Why a New Umbrella Theory is Needed}

Part 5 analyses one reason for economists' having learned so little about the economic faith, namely the existence of supply-demand "fundamentals" equilibrated by exchange rates. In other words, Part 5 analyses one reason for economists' having learned so little about clean floats, and about whether a managed float focused on stabilizing the exchange rate is inferior to the guarantee of invariance in the exchange rate via a currency union or a single world money. This reason is the omission under expected utility and game theory - and close relatives such as prospect theory - of the risk and uncertainty effects experienced in chronological time. The upshot is a trivialization and ignoring of the damage from unpredicted exchange rate changes.

The standard text employed in graduate schools to educate academic and official sector economists [12], Obstfeld and Rogoff, Foundations of International Macroeconomics is over 800 pages long. Yet it lacks a discussion of exchange rate uncertainty. Its chapter on financial uncertainty analyses uncertainty with essentially no reference to exchange rates being unpredictable. It analyses uncertainty primarily in terms of an infinitely long lived expected utility maximiser. This maximiser faces a probabilistically calculable future consumption stream, ${ }^{5}$

\footnotetext{
${ }^{5}$ Keynes recognised that investment returns cannot be probabilistically calculated a year ahead, let alone over an entire lifetime, as Rogoff and Obstfeld [12] assume. For critiques of this mainstream economics' assumption of probabilistically calculable futures, see [13] and [14].
} 
leading to an algebraically tractable solution, partly because the maximiser's sole objective is his consumption stream. This set-up enables graduate students to practice in this "uncertainty" chapter, like the other chapters of the book, tractable maximizing derivations over the extended future in Walrasian markets as if there were a single world money. ${ }^{6}$

Obstfeld and Rogoff is the state of the art text, whose mastering is a virtual pre-requisite for an academic or policy post in international economics. The book is impressive in its encapsulatation of the neoclassical expected utility approach for international trade, with some analogies to [15], Samuelson's Foundations. ${ }^{7}$ We take however a different view.

Neither the emerging graduate student - nor his lecturer taking him through Obstfeld and Rogoff text's 800 plus pages of univariate maximizations - is invited to go beyond its implicit exchange rate message, made explicit in [1-3], that exchange rate changes are harmless or beneficial. The economics international "expert" emerges from using this text without properly grappling with the fact that no economist has succeeded in generating a model that meaningfully predicts the exchange rate better than a random walk, so that episodically, the policy maker has to deal with the dramas of a world-wide liquidity shock, and if a policy maker in the third world, has to deal even more often with these dramas. The international "expert" emerges innocent of the fact that major exchange rate changes generate massive windfall profits and losses to those involved in real international trade, and massive windfall redistributions of wealth between international borrowers and lenders. This form of graduate education misses what Marglin [14, p287] terms the radical uncertainty inherent in multiple currencies. It accounts for the continuation of economists choosing to inject exchange rate liquidity shocks on the world long after the influential advocacy of variable exchange rates by Milton Friedman that aided in the demise of the Bretton woods Arrangement.

\subsection{A Fresh Umbrella Theory}

A fresh framework is needed instead of the myth of maximizing - and often (for algebraic tractability), infinitely lived maximisers- in expected utility and game theory and close relatives of these theories. It is necessary to include uncertainty effects during the stage when real world policy makers and academics make decisions, decisions moreover that neither the scientist nor the chooser can ascertain whether they are optimal, since the world is far too complex for anybody to formulate optimality, let alone ascertain whether optimality approximately holds. In addition the framework needs to include the uncertainty effects in the subsequent stages that choosers anticipate going through after making an exchange rate decision, and before learning

\footnotetext{
${ }^{6}$ There is a like irony of failing to grapple deeply with exchange rate uncertainty effects in [2]. The causes and effects of financial crises are not integrally connected to the chaos of unpredictable exchange rate changes. ${ }^{7}$ Indeed in sense it is even more encyclopaedic in that it includes interpretations of some econometric results through its lens - something infeasible for the original edition of foundations written when perhaps in that pre-computer age, the only econometric estimates available were those of Holland's Jan Tinbergen and Australia's Trevor Swan [16].
}

whether the outcome from their decision was good or bad. To this end, parts 6 and 7 introduce SKAT, the Stages of Knowledge Ahead Theory, and Part 8 offers within SKAT essential ingredients for a model to reflect the stylized facts of how exchange rates actually are set by policy makers, traders and other economic agents. In light of the key role of official sectors, we term a model with these ingredients a central bank conflict-cooperation model of exchange rate determination.

\subsection{Field and Laboratory Evidence}

Part 9 presents some field data as evidence that clean floats tend to generate exchange rate liquidity shocks. Part 10 describes the obstacles in using either armchair theorising or econometric estimates to progress beyond our simple field data evidence. Part11 details why a laboratory set-up can offer fresh insights. Part 12 presents the paper's experiment that is a particular central bank cooperation-conflict model of exchange determination. In it participants act as central bankers, governments, firms that import goods and speculate or hedge, and employer associations and unions as wage bargainers.

Parts 13 and 14 present the experimental results and conclude. Unlike the maximizing assumptions of expected utility theory - and its standard extensions such as prospect theory - the experiment allows us to interpret its results as resulting from the evaluation stage in each agent's decisions that affect the exchange rate. The experimental set-up is complex, since complexity is a hallmark of exchange rate markets, and false conclusions are drawn when either economists or experimentalists mimic mainstream economic theorizing and for the sake of tractability, over-simplify. Even though the experimental set-up, while complex, is exceedingly simple compared to the real world, the results disconfirm the ability of scientists and experimental participants alike to either discern an exchange rate equilibrium, or to accidentally enable it. The experimental results indicate that managed floats can keep exchange rates much steadier than they were in the clean float era of the early 1980s. There were however some serious outliers. The outliers reveal that a single world currency is the only reasonably safe way of avoiding exchange rate liquidity shocks. Finally, the experimental results point to the superiority of a single world currency for macro-management in each country, especially superior for maintaining international competitiveness. The experimental results thus disconfirm the widespread view that multiple currencies give a country's macro-management an edge. The new umbrella of SKAT can enable policy makers and academics to integrate the field and laboratory experimental lessons of exchange rate liquidity shocks in a coherent framework. This can avoid rapid forgetting and denial of damage from multiple exchange rates - damage from countries nationalistically choosing to have separate currencies partly on account of economists' lack of an umbrella theory that allows for radical uncertainty and its disastrous effects.

\section{CLEAN, DIRTY, MANAGED FLOATS AND EQULIBRIUM EXCHANGE RATES}

The clean float was originally promulgated under the belief that speculation is stabilising and that exchange rates 
would be far more stable than under Bretton Woods, Rogoff [3]. The concept of a clean or freely floating exchange rate is closely connected with Milton Friedman [17, 18]. It stemmed from closed economy modeling. It catered for US isolationist desires of not being pressured to conform to international pressures that its monetary policy (in funding the Vietnam War under President Richard Nixon) was too expansionary. In Friedman's version of the clean float, a central bank ought to focus exclusively on the domestic price level. In alternative versions that arose in the 1980s and continue to be promulgated today, the float was clean provided it focused exclusively on domestic goals and ignored exchange rate implications. ${ }^{8}$

Under dirty and managed floats, a currency's monetary policy includes the exchange rate as a goal in its own right. Under a dirty float, the official sector attempts to change its exchange rate in the belief that this will restore equilibrium. Under a managed float, as the term is used in this paper, the official sector uses exchange rate interventions, central bank currency swaps, interest rate changes, public announcements and fiscal policy in an effort to keep its exchange rate steady. For further details on the evolution and applications of clean, dirtyand managed floats, see Appendices 1 and 2.

The managed float perspective is independent of whether an exchange rate equilibrium is a meaningful or an empty and empirically disproven concept. By contrast both clean and the dirty floats rest on there being discernible equilibrium exchange rates. Under the clean float perspective, every exchange rate is equilibrating, provided that the official sector did not deliberately seek to alter the exchange rate. Under the dirty float perspective, under the joint internal (employment) and external (current account) equilibrium concept of Meade [19], ${ }^{9}$ the official sector alters the exchange rate to rapidly restore equilibrium in the wake of shocks despite sticky wages or prices.

Thus for both the clean and the dirty float perspectives, economists need to understand the fundamentals that determine exchange rates. To implement dirty floats, economists must in addition be able to predict reasonably accurately exchange rates in the short term to medium. As detailed in Parts 3 and 4 below, economists neither understand exchange rates nor can predict exchange rates in the short to medium term run.

\section{PRACTICAL ECONOMISTS' UNDERSTANDING AND PREDICTING THE EXCHANGE RATE}

Central bankers, despite their well-endowed research departments, bewail their inability to understand embarrassing and undesired changes in their country's exchange rate, e.g. [20, 21]. Major multi-nationals go into receivership through exchange rate errors despite access to

\footnotetext{
${ }^{8} \mathrm{~A}$ close relative of Friedman's clean float lens is [2] in which essentially the only mention of exchange rate crashes is a chart portraying close connection in emerging markets between currency crashes and inflation crises, with curiously, currency crashes defined as exceeding $15 \%$ per annum, but inflation crises defined with a threshold 5 basis points higher, of $20 \%$ per annum.

${ }^{9}$ We are indebted to Ed Nell on Meade's seminal place in arguments for official sector interventions to alter exchange rates.
}

the top commercial exchange rate experts. Currency blocs engage in trade wars since unable to implement the dirty float regime under which:

a) if one currency bloc has above equilibrium wages and prices, then the other currency bloc must have below equilibrium wages and prices; and

b) below and above equilibria wages and prices are objectively identified by means of an agreed-upon model employed by economists advocating for each currency bloc

An agreed identification of a) and b) has been rarely struck over the last 50 years. Instead, as documented in [16], the practice of dirty floats has been systematically of a beggar-thy-neighbour form, Appendix 3.

Has academic modeling - when removed from the hurley burley of the economists being located in central banks, firms or treasuries - had any more success in discerning exchange rate equilibria?

\section{ACADEMIC ECONOMISTS' UNDERSTANDING AND PREDICTING THE EXCHANGE RATE}

\subsection{Equilibrating Fundamentals}

Econometric models that incorporate equilibrating fundamentals fail after each new unanticipated exchange rate crisis. Each new crisis affords us a new pool of data. The prior theories fitted the earlier quarterly data just enough to get statistically significant coefficients, even if not nearly well enough to allow firms and governments to plan efficiently. But out of sample, those that are publicly available and checked, fail to outperform a random walk unless each data point is stretched from being a quarter in duration to two years in duration [22-25]. Out of each crisis, we acquire new generation theories. For a nice survey of this evolution [26]. Out of sample, some in the latest generation of publicly available ones do a little bit better than a random walk. ${ }^{10}$ However it continues to be the case that those available for public evaluation have a minimal degree of explanatory power [28]. ${ }^{11}$

Official sector econometric models yield predictions deemed inferior to asking the wise their hunch [30]. Some, e.g. Pagan, deem it fine if exchange rate models have essentially zero explanatory power in under two years - on the grounds that fundamentals are about long term factors not short to medium term ones. However firms need shorter term predictions to be reasonably sure of survival. Likewise

\footnotetext{
${ }^{10} \mathrm{An}$ example is improvements in measuring money stocks, including that reported in [27].

${ }^{11}$ One that employs fundamentals under standard competitive market assumptions but is not available for public evaluation uses Bayesian priors [29]. It suggests an impressive increment over investing in the S\&P 500. However no information is provided on this Bayesian prior enhanced model's degree of predictive power concerning individual exchange rates, or even concerning the set of exchange rates together used in its portfolio management strategy. Thus no evidence is afforded that its possible increment in exchange rate predictive power puts it anywhere near the level of prediction accuracy required to avoid firms going bankrupt. Firms continue to go bankrupt in their hedging mistakes, hinting that even this non-publicly available Bayesian priors technique leaves the economic equilibrating fundamentals unsatisfactorily vague.
} 
monetary officials need to operate within short horizons, above all in times like the financial crisis of 2007-9.

In addition, even within a two to four year range, the global financial crisis of the second half of this millennium hints at the need for a new generation of exchange rate models that have in their set of explanators factors like "repayments of funds to US dollar denominated creditors when these face a liquidity crunch". Without such explanators it would seem implausible that a new generation model could even retrodict the rise in the USD 2006-2008. But this class of explanators lies outside current notions of "fundamentals". Further the need for such liquidity shock explanators hints at the weaknesses in the whole neoclassical equilibrating conception of floating exchange rates.

\subsection{Understanding Despite Prediction Inability?}

It can be that economists understand fundamentals in the sense of being able to explain after the fact why the exchange rate changed without being able to predict the changes. This will be the case if the explanators are inherently unpredictable. Such indeed is plausibly the case, for reasons given in Part 8 and the presentation of our own central bank cooperation conflict model of exchange rate determination. $^{12}$ However even this does not mean that economists or anyone else can after the fact identify when a pair of countries is in internal and external equilibrium as per Meadian and neoclassical concepts. This would only occur if analysts can discern equilibrium under the conditions of complex reality as distinct from the simple worlds postulated in tractable algebraic models. Evidence of inability to discern such real world equilibria is inferable from the systematic biases that economists exhibit when claiming that they have done so [16] and Appendix 3 below, and from laboratory experimental evidence that players failed to recognize that the economy had been in equilibrium, Parts 12 and 13 below.

\subsection{Market Power}

Many, arguably most, exchange rate models have ignored the inefficiencies for firms and the official sector in having unpredictable exchange rates. These models rest instead on the possibility that the unpredictability could arise from efficient markets as in [31] and rational expectations. According to such models numerous EUT competitive profit maximizers use all available information in an efficient manner, and apply it to exchange rate markets, eg $\mathrm{Hu}$ [32] and argue that findings of inefficiency stem from using inappropriate tests, e.g. [33].

One quandary for this efficient markets viewpoint is the systematic and highly significant wrongly signed parameter estimate in interest parity models whenever the variation has sufficed to get sharp coefficient estimates [34]. An efficient market ought to operate to eliminate not exaggerate arbitrage opportunities. Yet for over five years on end in the 1980s, exchange rate expectations in highly regarded sources moved every quarter in the wrong direction as did the forward rates compared to the subsequent actual spot rates [35].

\footnotetext{
${ }^{12} \mathrm{We}$ are indebted to Bill Klein on the importance of distinguishing between unpredictable and unidentifiable fundamentals.
}

A second quandary is that the Fama concept of market efficiency is not a concept of the exchange rate simply being unpredictable. The Fama concept is an outcome of "rational" maximization of expected profits generated in the form of an equilibrium and thus bedeviled by the question of what is the equilibrium that the market so efficiently hovers around [36]. But it is implausible that equilibrium would be stable or unique given the negative findings with regard to other neoclassical, rational expectations and similar modelling. See e.g. [37-39].

The third quandary is that people do not instantly know the equilibrium. Instead it is proposed that they can learn it. But since the environment keeps changing, contrary to rational expectations, such learning is infeasible [40].

There is in addition to these three quandaries an overwhelming objection to such a Fama-Lucas world. This is the matter raised by Merton [41] and Soros [42] the matter of market power of key speculators that such models irrationally ignore. Merton [41] attributes Long Term Capital Management's difficulties to a failure to understand this hedge fund's massive market power and the actions of the fund's imitators and countermanders, factors assumed nonexistent in efficient markets arbitrage formulae.

Those with even more market power than private participants are the pair of official sectors who issue the pair of currencies. By law under full cooperation the two official sectors fully determine the exchange rate. The official sector currency swaps announced of 2007-2009 and revived in 2010 are examples of partial cooperation to stabilize exchange rates.

\subsection{Non-Fundamental Predictions}

If one deviates from equations predicting exchange rates on the basis of equilibrating fundaments, the picture is a little rosier. Technical analysis seeks to identify upper and lower barriers beyond which it is unlikely that an exchange rate will move, barriers at which it is predicted that there will be exchange rate turbulence, reversals of trends. The predictions can involve judgment in discerning the patterns, in which case it is sometimes termed chartism. Or the predictions can be mechanical, the product of fixed statistical rules.

Short range out-of-sample predictions based on some publicly available variants of technical analysis have attractive statistical properties, e.g. [43]. But again the degree of explanatory power is low. The inefficiency for firms and for the official sector in their joint inability to understand exchange rate changes remains drastic.

In summary, there is room for a radical change in understanding and modelling exchange rate determination. Before offering this, we explain why we also need to ground our radically different focus for understanding exchange rate changes in a different decision theory from maximizing theories, including EUT, axiomatised expected utility theory. EUT in turn is the justification for the treatment of probabilities in game theory and game theory's restriction of utilities to "end-points". 


\section{RISK EFFECTS AND EXPECTED UTILITY THEORY}

EUT, axiomatised expected utility theory, when consistently applied, excludes attributing utility to any segment of the outcome flow that occurs before all risk and uncertainty is past [44], and that remaining segment of the outcome flow must, as Friedman and Savage [45] put it, be evaluated "as if certain". This is not a promising basis for discerning the operation of exchange rate markets. It puts blinkers on economists that inadvertently exclude the effects that uncertainty actually has on the value of outcomes. Small wonder that scientists dissecting [46], Mundell's optimal currency area model, focus on numerous dubious features of the model, but few on its assumptions of certainty discussed in Appendix 3 of this paper. I.e. few focus on the fact that in [46] the exchange rate is certain: nobody before and nobody after the exchange rate change (to restore equilibrium after a shock) ever expects there to be another exchange rate change!

In reality, from the point of choice, a decisionmaker faces an outcome flow in the form of a chronological sequence of outcome segments from which he derives utility. By contrast, under EUT and its standard atemporal rank dependent generalisations such as cumulative prospect theory, each outcome is a timewise indivisible outcome segment that is the final outcome segment after all risk is past [47-49]. Thus such theories have jumped through and ignored earlier periods during which the decisionmaker faces risk and uncertainty- jumped into the more distant chronologically indivisible future when all risk is past and certainty reigns. This static feature was admitted by von Neumann and Morgenstern and in Friedman and Savage $[45] .{ }^{13}$ This static feature excludes EUT dealing consistently with any serious economic issue. Loans (and their exchange rate risk premia interest rates) for instance require a future chronologically divided into at least two distinct stages of knowledge ahead, (i) the risky periods $0 \leq t<k$ of Fig. (1) during which the loan is enjoyed, and (ii) when the risk is past, $t \geq k$ of Fig. (1), and if it turns out that the borrower is solvent, the loan is repaid. ${ }^{14}$

EUT's ignoring of risk in mapping outcomes $Y_{x}$ into utilities can be seen from the right hand column of Fig. (1) where the probability distribution - that denotes the chooser's degree of risk, i.e. of knowledge ahead - does not affect $\mathrm{U}_{x}$, the utility of outcome $x$. Under EUT, for a risky choice $\mathrm{V}$, its utility is,

\footnotetext{
${ }^{13}$ But from 1950, in a tradition continued since, Marschak ignored the static constraints that the axioms impose and to which von Neumann and Morgenstern had alerted scientists, and re-expressed the axioms with a contradictory interpretation of outcomes as having multiple chronological segments. For details on Marschak, see Appendix 4.

${ }^{14}$ To recognize Marschak's error, note that under EUT axioms, any probability distribution can be thrown over the entire set of mutually exclusive outcomes. Suppose that this set comprises 2-tuples, denoting consumption in periods (i) and (ii). Let one such outcome be $(100,200)$ and another $(50,150)$. Then EUT requires that a $50 / 50$ chance of these two outcomes is a meaningful distribution. But it is meaningless/ infeasible since in period (i) the risk is unresolved, so that these two outcomes must have an identical outcome segment as observed/proven in [47-50].
}

$\mathrm{U}(\mathrm{V})=\sum_{x=1}^{X} p_{x} \mathrm{U}_{x}$

where $\mathrm{X}$ is the total number of mutually exclusive outcomes, and $p_{x}$, the probability of outcome $x$. Nothing that is anticipated to happen in chronological time during the risky periods $0 \leq t<k$ is in EUT's equation (1). The only way risk enters EUT is atemporally, in how probabilities concerning the mutually exclusive outcomes aggregated to attain a single overall value of the alternative. Under EUT the atemporal aggregation rule is simple probability weights. Under cumulative prospect theory and other standard rank dependent generalisations, the atemporal aggregation rule is a more complex (de-) cumulative probability function, but still no real time risk effects are included as the anticipated utility mapping is identical to that of equation (1).

See Appendix 4 on the numerous attempts to remedy this omission and why each attempt fails. See [48-50] on why EUT cannot include more than one period, even after all risk is passed. See $[50,51]$ on how including in the utility mapping any risk effects anticipated to be experienced - i.e. anticipated to occur in future time periods - precludes deriving EUT's representation theorem.

\section{THE VON NEUMANN AND MORGENSTERN CONTRADICTION}

Keynes had been interested in financial effects of uncertainty that fall on the investor following a decision to invest [52, pp52-65]. Von Neumann and Morgenstern had recognized that EUT missed out on some emotional uncertainty effects such as excitement that occur following a decision to gamble socially, ones to which they gave various names including the utility of gambling. They had wished to expand their model to include them, but left the task to future researchers as they could not solve a contradiction that they encountered "on this level" [53, pp428-432]. To include choosers' anticipations of these uncertainty effects meant admitting that choosers were affected by the distribution, i.e. by an interdependence between the different possible outcomes. But, asked von Neumann and Morgenstern, when each outcome in the distribution is mutually exclusive, how can a chooser be affected by their interdependence? ${ }^{15}$

To get to the higher level where mutually exclusive outcomes can be interdependent (without the chooser being irrational), it is necessary to partition the future epistemically, by stages of knowledge ahead. Upon making a risky choice, the chooser goes through what may be termed a pre-outcome period, a period of uncertainty, of ignorance of the final segment of his outcome flow. During this period, since the risk is still unresolved, there can be an interdependence of the mutually exclusive outcomes in the chooser's mind [54]. The chooser can hate or love the excitement of the tension created by wondering whether the good or bad outcome will occur, i.e. created by the interdependence of the good and bad outcome - created by

\footnotetext{
${ }^{15}$ In the language of quantum physics for which von Neumann had constructed an axiomatisation ten years earlier, they termed this interdependence a complementarity.
} 
$t=0$

Choice

a risky act i.e. an act with at least two different possible post-risk segments of the outcome flow

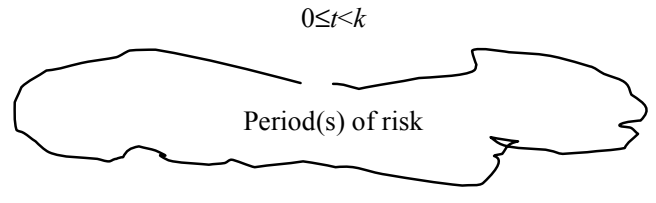

These segments of the outcome flow are jumped over and ignored even though they occur after $t=0$ $t \geq k$

Period after risk is past

Utility $U_{x}=\mathrm{U}\left(Y_{x}\right)$ of each different possible post-risk outcome segment

Fig. (1). The jump through of the prior periods of uncertainty to certainty that occurs under EUT and its standard rank dependent generalisations.

Table 1. Four Epistemic Stages upon Encountering a Problem at Time $t=-2$

\begin{tabular}{|c|c|l|l|}
\hline Stage & Duration & Period & Knowledge \\
\hline \hline 1 & $-2 \leq t<-1$ & pre-choice set: & prior to identifying the choice set \\
2 & $1 \leq t<0$ & pre-choice: & prior to choosing an act within the choice set \\
3 & $0 \leq t<\mathrm{k}$ & Pre-outcome & prior to learning the outcome of the chosen alternative \\
4 & $t \geq k$ & post-outcome: & knowing the outcome of the chosen alternative \\
\hline
\end{tabular}

the non-degenerate probability distribution over the outcome space. Later, at the beginning of what may be termed the post-outcome period, the chooser learns the result of his choice, i.e. the later segment(s) of his outcome flow, has attained certainty. But through historical legacy there may remain effects of the prior uncertainty.

SKAT, the Stages of Knowledge Ahead Theory, dissolves the von Neumann and Morgenstern contradiction, and integrates earlier work on emotional risk effects with that on planning efficiencies via risk effects. It allows us to identify other material and financial risk effects, to delineate the mutually exclusive cause effect chains that choice of an alternative would unleash - and to avoid conflating these anticipations with atemporal weights used to aggregate these mutually exclusive cause effect chains. For details on how this is effected, see Appendix 5 below and $[50,55,56]$.

\section{SKAT'S EPISTEMIC STAGES}

The process of decision making starts before the point of choice at which EUT begins and at which each alternative V is evaluated in Fig. (1). There are at least two prior substages. See the first two rows of Table 1 and the first two columns of Fig. (2).

Each stage ends with a change in knowledge ahead about a different matter. Stage 1 ends when the choice set, previously unknown, has been discovered. Stage 2 ends when the choice, previously unknown, has been made. Stage 3 ends when the final segment of the outcome flow has been learned. (At the point of choice it is unknown unless Stage 3 is degenerate since a sure act is chosen). ${ }^{16}$

\footnotetext{
${ }^{16}$ After encountering a problem, there can be a vast number of stages as new things are learned, almost minute-by-minute. The reduction to only four epistemic stages in Table 1 and Figure 2 is because these portray the simple case where: i) each change in knowledge is from ignorance about some future happening - i.e. at best probabilistic knowledge of what that happening may turn out to be - to certainty about that happening (to that risk being completely resolved; and ii) there is no returning to earlier stages
}

All that von Neumann and Morgenstern and EUT include is stage 4 , the final row of Table $\mathbf{1}$, and the final column of Fig. (2). But stage 4, the post-outcome period only begins upon learning the outcome of the chosen act (and that lasts indefinitely in our simple scenario, not being followed by any other change in knowledge ahead). As can be seen from Fig. (1), EUT ignores the period of discovering alternatives and evaluating them. It assumes that the chooser can instantly and costlessly know the choice set, evaluate in a maximising way each of the available alternatives to choose, and then leap through the period of risk and uncertainty. EUT thus maps into utility only the final segment of the outcome flow that began upon learning of the problem. For the case where the chooser selects a risky act with, at the point of choice, multiple possible outcomes $Y_{i}, i=1,2, \ldots$, EUT attaches utility only to the outcome flow segment after the chooser has learned which final outcome segment has transpired - and attached utility to this final segment in a knowledge ahead independent way. That is, EUT evaluates each possible outcome as if there never was earlier any risk or uncertainty, as if the future were certain. Thereby when used consistently without importing additional contradictions, EUT excludes all real time effects of risk and uncertainty in the initial three stages, and also excludes any real time historical legacies of this prior risk and uncertainty in stage 4.

\subsection{Primary and Secondary Satisfactions}

Satisfactions (future real time experiences)can be positive or negative (dissatisfactions). Choice depends on satisfactions as anticipated at the time of choice, and discerning their real time risk effects is aided by distinguishing primary from secondary ones. Primary satisfactions stem from knowledge-ahead-independent sources of satisfactions. Primary satisfactions from the

as happens if e.g. in the pre-choice (evaluation) stage a new alternative to evaluate is discovered. 


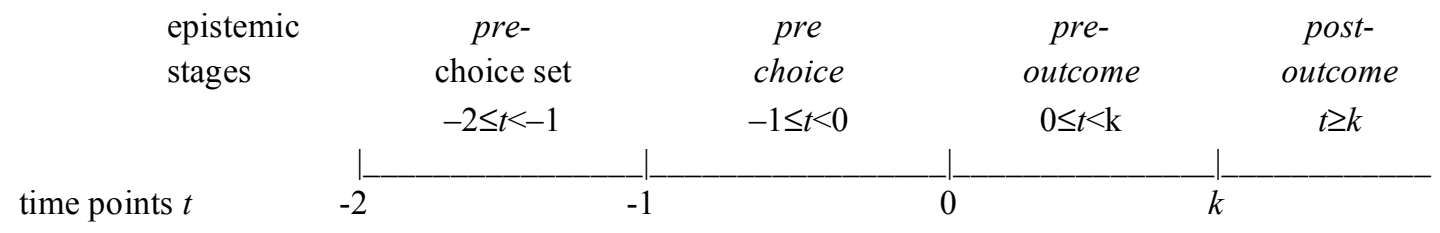

Note:

1 The name of the first three periods starts with "pre-" and then states an aspect of the future that the person will not yet have learned, namely in stage 1 the choice set, in stage 2 the choice, in stage 3 what will be the outcome of the choice, a stage that is degenerate, of zero duration, if the choice is a sure act, as then the chooser knows at the point of decision $t=0$ the outcome, i.e. in this case $t=0=k$. If instead the choice is a risky act, stage 3 , like the other periods, is of positive duration, ie $t=k>0$. The last stage starts with "post", and then states the aspect of the future the person that the chooser by then have learned, namely the final segment of the outcome flow.

2 Each of the four time points-2,-1, 0 and $k$ denotes a change in knowledge ahead, with one previously unknown aspect having become known, and the start of a new epistemic period that lasts until the next change in knowledge ahead.

3 In the case of choosing a sure act, the outcome of the chosen act is already known. Thus for sure acts the time points $t=0$ and $t=\mathrm{k}$ coincide - are simultaneous - and the duration of the pre-outcome period is zero. It is only for risky acts that the time points $t=0$ and $t=k$ fail to coincide - are non-simultaneous - so that the pre-outcome period is of positive duration. The false simultaneity postulate in von Neumann and Morgenstern [53] leading to their contradiction, had two prongs. Prong a) was to explicitly set $k$ to be simultaneous for all acts in their explanation of their axiomatisation. Such simultaneity is incompatible with the theory including both sure and risky acts, when these are distinguished from each other by whether there is full or merely limited knowledge ahead of the outcome at $t=0$. Prong b) was to implicitly set $k=0$ for both risky and sure acts in the atemporal axioms (ones lacking any epistemic division of the future from the point of choice).

\section{Fig. (2). The Future Divided Epistemically - by Changes in Knowledge Ahead}

outcome segment that occur after all conceivable risk is past, are included in EUT. ${ }^{17}$ To be knowledge ahead independent, satisfactions must be reaped from each current segment of the outcome flow independently of having known ahead what this outcome segment would be. An example of a primary satisfaction in a particular segment of the outcome flow is a portion of the satisfaction from money spent on current consumption.

During that particular segment of the outcome flow, there will also be secondary satisfactions arising from what might otherwise have been (e.g. disappointment as the money could have been more) and from what might be (e.g. hope that in the following segment of the outcome flow that the money might be high, and fear that it might be low). Secondary satisfactions can also be financial from what might have been (e.g. the decisionmaker might be fired because others expected in that segment more money) and from what might be (e.g. paying a hefty risk premium because the decisionmaker's banker considers that the decisionmaker might in the future segment of the outcome flow default on a loan), or from what will be (e.g. safety and efficient planning since a safe alternative with a certain future was chosen).

Secondary satisfactions are termed secondary since they derive from primary satisfactions, not because they are necessarily less important. Often they are more important. Since in the case of secondary satisfactions, satisfactions derive from the outcome's riskiness or certainty, it is infeasible to trace out the secondary satisfactions function on

\footnotetext{
${ }^{17}$ If as EUT and most non-EUT theories do, we limit ourselves to utility itself being inherently univariate and mappable into money, the utility shape with respect to money is concave if there is diminishing marginal utility from primary satisfactions, linear if there is linear marginal utility from primary satisfactions, and convex if there is increasing marginal utility from primary satisfactions, as in the famous diagrams of Friedman and Savage [45]. In that paper, primary satisfactions are what Friedman and Savage term the EUT utilities, being unaware that there might be certainty effects captured by their version of EUT, and recognizing that EUT excludes from its utilities sources of satisfactions based on a limited degree of knowledge ahead.
}

a plane with outcomes on the other axis. Multiple other dimensions (axes) will in general be needed to capture the various aspects of risk whose bound at one end is certainty.

Secondary satisfactions stemming from a limited degree of knowledge ahead destroy the axiomatic base of EUT, and most non-EUT theories. As regards exchange rate changes, an example of a negative material secondary satisfaction is the planning inefficiency of a central bank not knowing whether its attempt to hold out against speculators will succeed. If it knew it would fail it would not waste any taxpayer dollars in interventions on the exchange rate market seeking to defend its currency. If it knew it would succeed, it would not damage its economy by raising interest rates or in other ways restricting domestic credit. It is its limited degree of knowledge ahead of whether it will succeed that results in its "half-way" measures because it does not know what will ensue and thus must inefficiently invest with a bet each way.

Another example of a negative material secondary satisfaction for the central bank is the higher risk premia faced by its country's government and firms in borrowing outside its currency block if the currency fluctuates substantially, as is the case for Australia and New Zealand. This is a secondary satisfaction since the loan size and its repayment cost inclusive or any risk premium interest surcharge depends on degree of knowledge ahead - namely the probability of repayment. Exchange rate depreciation risk for the borrower's domestic currency adds to these negative secondary satisfactions for the borrower by increasing a) the risk of default and thus risk premium, and b) the repayment liability if solvent.

An example of a mixed emotional and material secondary satisfaction often faced by policy makers is blame when a risk turns out badly. Its emotional component is the affect. Its financial component is the loss of income or promotional prospects in the case of official sector executives moved sideways or with their powers relegated to another branch as happened after the bad outcome of the Black Wednesday 1992 pound depreciation. The bad 
outcome and blame resulted in the UK Treasury's power over a key interest rate being relegated to another branch of the official sector, namely the Bank of England.

\subsection{Non-Maximisation in the Evaluation Stage}

When EUT skips all stages apart from the final postoutcome one, it assumes that evaluation is costless and timeless and can be a maximising process. Such maximising however is infeasible, even to define and thus impractical to conduct. As Savage [57] observed, it is beyond our scope, even for a family picnic. Savage sought to solve this practicality issue via maximising under a small worlds assumption. But identifying how it could render EUT practical, he found too difficult a task, and left it to future researchers. To the authors' knowledge, no progress has been made since on rendering small worlds, and thus EUT, practical.

Savage also tried another angle to substitute for explicit maximising, a clarifying sure-thing principle. But this has two shortcomings. First, it cannot be applied in most circumstances. Second where it can be applied it "clarifies" by truncating the probability distribution creating a delusion of certainty [58] - i.e. it is a patently irrational principle.

SKAT, by contrast, permits the outcomes segment to include the evaluation stage and thus the non-maximising techniques that central bankers report using, e.g. [59] and that economists analysing central bank minutes, report that they use, e.g. [60]. This is likewise the case for others whose actions influence exchange rates. Thus [61] illustrates SKAT for the Bank of England's situation in the face of the speculative attack on the pound in 1992 culminating in inadequate official sector cooperation and Black Wednesday. Appendix 6 below illustrates SKAT for the Banque de France that faced a speculative attack on the French Franc in the following year with a very different outcome due to a far greater degree of cooperation from the Bundesbank.

\section{AN OFFICIAL SECTOR COOPERATION- CONFLICT EXCHANGE RATE MODEL WITHIN SKAT}

SKAT permits us to start at the beginning of this process for the key participants in the exchange rate process. In EUT and its temporal extensions and standard rank dependent generalisation, the decision process starts half way through. In these, a choice can be costlessly and instantly made since each alternative has been costlessly and instantly evaluated via a maximising technique. SKAT, by contrast, allows us to start earlier, and in starting earlier, recognise the infeasibility, impracticality and non-employment of maximising techniques in choosing an alternative.

\subsection{The Key Players}

As in any modelling, we must abstract, we thus focus on key players in exchange rate determination, not on those with marginal influence. In exchange rate determination, the key players are the issuers of the currencies, and those who decide how much is to be issued and under what conditions. In this regard our focus accords with that advocated by Soros $[42,62]$. Soros has been decisively more successful in predicting exchange rate changes than most of those who employ standard models that ignore the market power of key players and apply efficient markets formulae.

Today private bank currencies can be ignored. Each currency area is supervised by an official sector that has the power to:

1 produce in unlimited amounts its own currency and 2 intervene on the foreign exchange market.

For some currencies, powers 1 and 2 both reside exclusively in a central bank, e.g. for the EURO. For some currencies, e.g. for the US dollar, there was historically a sharing of these two powers between the central bank and the treasury. For yet other currencies, e.g. the Australian dollar, there is a sharing of these two powers among three branches of the official sector, the central bank, the treasury and the parliament.

Powers 1 and 2 together imply that for each pair of currencies, total cooperation of the official sectors totally settles the exchange rate. No speculator whether private or a third country's central bank has any scope to deflect the exchange rate over any significant period of time. For an hour or two, there can be some deviation - since one of the central banks may have misestimated the extent to which intervention was required. But apart from these minor transient frictions, the exchange rate is set.

\subsection{Behaviour of the Key Players - Their "Reaction" Functions}

All unwanted exchange rate changes fall on a country from lack of complete cooperation of the two official sectors. In this respect the situation of a modern official is similar to that of the gold standard era. That was not maintained by automatic mechanisms pertaining to how monetary policy influences prices or interest rates or capital flows. Among the major players, it was maintained via the gentlemen's club. ${ }^{18}$ Central banks co-operatively shipped gold and silver and engaged in reverse rediscount rate changes as required [64]. Such cooperation is dependent on individual personalities and cultures. It is disrupted by changes in who were the central players and their degree of cooperativeness. The disruption after the First World War (which gave key roles to non-cooperators, the US and France) ended the gold standard [65]. There was a like failure of co-operation for the incipient EURO group in the stances taken by Germany and the UK when unexpectedly needed, precluding at least temporarily, UK participation in the EURO. There was limited cooperation, sufficient to limit the depreciation of the French franc, between the French and German official sectors the following year. Overall, Cooper in his highly informative review [66] concludes that there has been a growing degree of central bank cooperation on exchange rate management and other matters over the 50 years of the existence of the central bank organization founded to achieve this, namely the Bank of International Settlements.

\footnotetext{
${ }^{18}$ Among minor players on the world stage who had difficulties staying on the gold standard, official sectors of the big players as well as commercial banks assisted the process [63].
} 
As Paul Volcker reports in an interview [67] the US exchange rate is also a matter of cooperation among official sectors. He explains that the era of a high dollar in the 1980s ended after the British Prime Minister Margaret Thatcher discussed the matter with Ronald Reagan. Without such cooperation of a personal friendship, Germany's central bank had shortly before tried with insufficient success to unilaterally get the US dollar down via exchange rate market interventions. ${ }^{19}$ Margaret Thatcher's friendship with Ronald Reagan achieved the desired cooperation. She informed Reagan that the damage being wrought on other countries (from the roughly doubling of the value of the US dollar and the roughly doubling of world wide interest rates) was unsustainable. Reagan is reported to have understood and agreed. He had also been facing years of complaints from exporters and others affected by the severe prolonged recession in the US. ${ }^{20}$

\subsection{Our View of the Exchange Rate Formation Process}

Our approach in its general form is an extension of that in Pope [15]. It was extended from the single official sector with neutral other central banks, to the game theoretic perspective introduced by Reinhard Selten's inquiry about central bank conflict. It was further refined by Jürgen von Hagen's interest in the distinct role of the government's fiscal policy independently of how the central bank as a separate organisation considered should be the stance of fiscal policy and despite the fact that both entities had a shared objective, namely the common good of their stakeholders. This in turn reflects the assignment issue first raised in a seminal paper on how macroeconomic objectives should be split between the treasury and the central bank, Swan [73]. Mundell [46] discussed Swan's assignment for

\footnotetext{
${ }^{19}$ Such was the false belief in free floats, and in the helplessness of central banks at this time, that Dieter Sondermann reports as follows. The general view of exchange rate dealers was that the Bundesbank's unilateral interventions were counterproductive: they enticed dealers to think that the US dollar's rise really would have no end and via such anticipations, to push the US dollar yet higher. However access to the daily data, and analysis thereof, suggests otherwise [68]. See also [35, 69-71] On the other techniques besides intervention for an official sector to unilaterally influence its exchange rate, see [72].

${ }^{20}$ After Maggie Thatcher's conversation with him, the combined set of official (fiscal and monetary) policies in the US altered in a way that the US dollar's value, had returned to its early 1982 level by the end of the 1987, as had interest rates, a change aided by a switch in who was White House Chief of Staff and who was the Treasury secretary. The switch meant that the Treasury was no longer headed by the devout clean floater Donald Regan, but instead by the pragmatic Howard Baker. This episode is thus interpreted as a case of belated cooperation of the official sectors of the UK and the US. It resulted in a return of the exchange rate between the US and other countries to what a set of influential countries deemed to be the appropriate level. The cooperation, signed in the Plaza Accord (among the big five), went beyond an agreement to stabilise exchange rates henceforth. It involved in effect reversing what had happened over the last three years, roughly a doubling of these four exchange rates in this brief span. For Japan moreover, it involved a much faster doubling. Further, Japan, unlike the other "big three), had not had such a marked depreciation of its currency in the 1980 s, so that the shock for Japan of its currency almost doubling in value was far greater. By 1987, the official sectors of big currencies had realised that both appreciations and depreciations and also their unpredictability were bad. In the Louvre Accord, they agreed to keep major exchange rates stable. That is, by 1987 there had been complete reneging on the virtues of clean floats, and effort instead to have an informal Bretton Woods with gentlemanly central bank cooperation.
}

the case of whether fixed or flexible exchange rates are better.

A key feature is the power of fully cooperating official sectors operating currencies, to fully set their pairwise exchange rate. Cooperation involves:

\section{a) sacrificing other official sector interests and}

b) fending off unwanted private sector pressures.

Conversely, the extent to which exchange rate changes are undesired by one of the two official sectors, or even simply unexpected by one or both of them, can be characterised in terms of degrees of conflict between the two official sectors as regards: whether interest rates set assist in stabilising the exchange rate or in moving it to a jointly agreed upon new rate; official sector announcements of their exchange rate goals; official interventions; domestic price and inflation goals.

Using historical episodes as reported by key official sector participants in the exchange rate process, we identified the following.

(i) A few individuals (who control each currency area's official sector), among themselves determine that official sector's degree of cooperation or conflict with each partner official sector.

(ii) These people are human beings who cannot and do not use maximising procedures to reach decisions.

(iii) The personalities of those in these official sector roles with their resultant group dynamics matter something not captured by assumptions of an unchanging culture and associated "reaction function" of the particular branch of the official sector.

(iv) Even where the Treasury (finance department) of a government has no power over the issue of notes or coins or over foreign exchange rate interventions, through its fiscal and trade policy, it has an impact on exchange rate determination.

(v) Within the entire official sector (central bank, Treasury, State Department, Banking Supervisory Units), multiple instruments are available for implementing monetary policy. Instruments include the setting of the terms for some interest rates, portfolio choice for the composition of central bank assets, any scope to set reserve requirements or emphasis on adherence to legal or implicit safety levels, announcements of official sectors and orders or requests to financial institutions. Assertions that the official sector has only one monetary policy instrument are false. Such assertions stem from the excessive simplifications employed in the algebraically oriented university education of economists.

(vi) Multiple objectives often enter official sector exchange rate decisions. Assertions that monetary policy is invariably geared to a domestic price/inflation goal are false and relate to the excessive simplifications employed in the 
algebraically oriented university education of economists. For major currencies, only for short periods between exchange rate liquidity shocks has the clean float conception of monetary policy exclusively geared to a domestic price/inflation goal been implemented. Over longer periods spanning an exchange rate liquidity shock, official sector monetary policy objectives of major currencies are better characterised as comprising at least seven goals, 1) stability of domestic prices, 2) forecastability of domestic prices, 3) appropriate interest rates, 4) national pride in meeting exchange rate objectives, 5) maintaining international competitiveness, 6) avoiding domestic overemployment, and yet more important, 7) avoiding domestic underemployment. Often after an exchange rate liquidity shock, there is also until more forgetting sets in, an additional objective 8) of financial stability.

Our viewis thus that any model must embed the following seven features.

1 A pair of official sectors that agree on a desirable exchange rate, and fully cooperate to attain it, set their exchange rate.

2 Incomplete cooperation or conflict between a pair of official sector opens the way for influence of the private sector, but such private sector influence is confined confined to the range of disagreement between the central banks on where is the exchange rate that each is willing to defend.

3 Official sectors are hierarchical, with their decisions made by a few influential people.

4 These influential decisionmakers use non-maximising techniques - heuristics - in reaching choices.

5 Individual differences in the people holding power in these official sector hierarchies matter.

6 Fiscal policy matters.

7 Each official sector has typically multiple goals.

These seven features render our model radically different from those with reaction functions of maximising central banks, at most a couple of objectives, and no allowance for personalities, friendships, enmities and so forth between personnel heading either the central bank or treasury or parliamentary components of official sectors. Our model differs even more radically from the majority of models of exchange rate determination as these do not include an official sector explicitly at all, considering only "fundamentals" and different sorts of private operators on the exchange rate market. For instance there can be a mix of "informed" traders who employ a specific "fundamentals" model and "uninformed" traders who either seek to copy the informed traders or to employ chartist or other techniques.

As regards currency traders, our model is rather standard, namely allotting a role to those firms effecting currency sales for purposes of trade in goods and capital. What makes it non-standard is our recognition of how circumscribed is the role of the private sector. We shall describe a particular version of our model in Part 11, the one that underlies a laboratory experiment. First we offer in Part 9 some simple field evidence, and outline in Part 10 obstacles in going much further than this simple evidence using either an algebraic approach or econometric estimation.

\section{OUR FIELD EVIDENCE}

As detailed in our introduction, in this paper, the term liquidity shock is used in the generic Keynesian sense of a massive (unpredicted) change in the price of an asset. ${ }^{21}$ An exchange rate liquidity shock will be exacerbated if it is accompanied by an unpredicted rise in the cost of borrowing, or unpredicted inability to borrow. Such shocks endanger not merely the financial sector but the entire real sector of any economy.

There are many countries and thus many exchange rates. Let us use a broad brush in our field evidence on whether clean or managed floating stabilises the exchange rate better. Let us focus on just two trading blocs, namely the US and those who entered the EURO. From 1970 until into this millennium, these two blocs have had the other as their key trading partner. ${ }^{22}$ Let us focus on just the exchange rates of these $v s$ the US dollar.

The1998 and 2001 incipient exchange rate liquidity shocks for this set of countries were averted by the equivalent of managed float operations. For details, see e.g. [74]. This part of the paper examines the two actual exchange rate liquidity shocks for this set of countries: (i) the unpredicted doubling of the USD in value in the early 1980s; and (ii) the unpredicted abrupt rise in the USD in value 2006-2008.

Consider first (ii). It arose after the EURO had been formed with a clean float mandate and after non clean floater Alan Greenspan had been replaced as chair of the US Federal Reserve Board by Ben Bernanke. On taking over, initially Ben Bernanke was decidedly more of the clean float persuasion, ${ }^{23}$ focusing on incipient inflation dangers and raising official US interest rates on the eve of the exchange rate liquidity crisis that was beginning in mid 2006. The unintended abrupt rise in the USD from mid 2006 can be attributed to numerous key currency official sectors taking a primarily clean float perspective.

The extent of the 2006-2008 exchange rate liquidity shock was mitigated by central bank swaps. The US Federal Reserve organized these with the European Central Bank and

\footnotetext{
${ }^{21}$ Thus in this paper, as in Davidson [13], the term liquidity shock is not limited to the case where people retreat entirely from commercial assets and from transactions and put their savings under the mattress as in the narrower interpretation of this term. In this paper the term liquidity shock includes also situations where people have a "flight to safety" shock that massively and unpredictably alters relative asset prices.

${ }^{22}$ In the 1970s and to date, the EURO countries have been the US's most important trading partner. This was also true in the reverse direction until into the current millennium (statistical sources, the US Federal Reserve System and the European Central Bank). In terms of capital flows, the other key determinant of exchange rates, it is reasonable to postulate that in both directions, the EURO bloc and the US have found the other its key partner.

${ }^{23} \mathrm{His}$ appointment was hailed as an opportunity for the transparency of a clean float regime, e.g. [75].
} 
Swiss banks in December 2007, and extended them to numerous other developed and developing countries in the wake of the disorderly collapse of the giant investment banker Lehmann Brothers on September $15^{\text {th }}, 2008$. The US Federal Reserve took foreign currencies as collateral in the swaps, but more importantly, had the full commitment and confidence of the participating central banks as surety. These central bank swaps were orchestrated in light of banks, particularly foreign banks, putting pressure on USD money market rates (in their efforts to get USD to roll-over debts denominated in USD as the US sub-prime crisis deepened and extended. These firms were facing abrupt rises in the cost of USD and in interbank interest rates, when indeed interbank loans were available at all.

Following the central bank currency swaps, many exchange rates with the USD by early 2009 had returned to their mid 2006 level, the level prior to the sharp rise in the value of the USD as borrowing became more difficult progressively precluding firms from rolling over their USD denominated debts. It is implausible that the rise in the value of the USD would otherwise have ceased so soon and reverted toward its pre crisis level so rapidly. It is plausible that without the central bank currency swaps, the USD liquidity drought would have been many times more drastic.

But this curbing of the USD liquidity shock via central bank swaps cannot be described as an instance of a managed float policy implemented in order to stabilize exchange rates. Rather the exchange rate stabilization was an incidental virtually unremarked outcome of the swaps initiated to make it easier for the US Federal Reserve to manage its Federal Funds rate.

As the value of the USD receded in the wake of the currency swaps, China expressed doubts about continuing to hold so many USD's. US Secretary of State Hilary Clinton in February 2009 used diplomacy to seek to persuade China to buy more US Treasury Bills. The Chinese foreign minister Yang Jiechi is reported to have informed Clinton of its hope that these US Treasury Bills remain for China a safe and liquid investment [76]. For US Treasury Bills to remain liquid for China, and not become illiquid (i.e. subject to a massive unanticipated adverse price change), the Yuan USD exchange rate needs to remain fairly stable.

It is however far from clear whether the US official sector comprising the US Treasury and the US Federal Reserve jointly endorses a policy of a managed float aimed at this exchange rate staying constant. The US Federal Reserve perhaps seeks this. But it and the US Treasury continue to face pressures from politicians representing exporters and its import competing sector who believe that a lower USD would boost employment and output. Further many US academics and think tanks, including the prestigious Peterson Institute of International Economics, favour a lower USD to reduce the country's current account deficit. It is thus unclear whether Hilary Clinton's requests to the Chinese to continue buying US Treasury bills marks a switch in US policy to an exchange-rate-stabilisin managed float. It perhaps merely points to conflict within US policy making between (i) those jockeying to continue the managed float policy to get the USD depreciated against the Yuan, and (ii) those jockeying to stabilize the USD against the Yuan, the EURO and other key currencies.

It is similarly unclear to us whether the ECB's acceptance of US Federal Reserve currency swaps was in order to stabilize the exchange rate. Does its initiation of such swaps with other currencies in its region, and the revival of swaps with the US Federal reserve in the 2010 Greek crisis, herald a switch from the ECB's former closed economy clean float rhetoric, and arguably formerly actual clean float policies? The answer is no if we may judge from the US Federal Reserve 9 May FOMC statement. The renewal of central bank swaps was simply in order to furnish liquidity in USD (implicitly to foreign banks with customers having difficulty in rolling over USD denominated debts). ${ }^{24}$

Let us now consider the exchange rate liquidity shock of the early 1980s. For both the US and those countries that would become the EURO bloc, the clean floating hey day was the early $1980 \mathrm{~s}$. In commencing on his clean float fight inflation first goal in 1979, the incoming US Federal reserve Board chair Paul Volker did so under strong pressure to be cooperative and adopt this view espoused by his German central bank counterpart, Otmar Emminger [77] and [78]. The Plaza Accord of 1985 and the Louvre Accord of 1987 were essentially transatlantic government agreements to undo the exchange rate changes that arose under the clean floats. ${ }^{25}$ For the transatlantic bloc, if the clean float viewpoint holds, we might have anticipated that, compared to the 1980 s, annual exchange rates would be more volatile in the 1970s, 1990s and in this millennium - as the floats in these other eras were more managed. The reverse prediction holds under the managed float viewpoint, namely exchange rate volatilities should be higher in the 1980s. See Table 2.

Table 2. Annual Exchange Rate Volatilities with the USD

\begin{tabular}{|c|c|c|c|c|}
\hline & Italy & France & Germany & EU 12 \\
\hline \hline $1971-1980$ & 0.06 & 0.07 & 0.07 & 0.06 \\
$1981-1990$ & 0.14 & 0.14 & 0.12 & 0.13 \\
$1991-2000$ & 0.07 & 0.07 & 0.07 & 0.07 \\
$2001-2008$ & 0.07 & 0.07 & 0.07 & 0.07 \\
\hline
\end{tabular}

The annual exchange rate volatilities were symmetrised to avoid discrepancies between percentages being affected by which way the exchange rate is expressed, and thus by whether the former or later exchange rate is higher. The symmetrisation was done by taking the average of the absolute annual percentage increments $\left|e_{t}-e_{t-1}\right| / e_{t-1}$ and $\left|e_{t}-e_{t-1}\right| / e_{t}$. This average in turn simplifies to $0.5^{*}\left|e_{t-1} / e_{t}-e_{t} / \mathrm{e}_{t-1}\right|$, where $e_{t}$ is the exchange rate in year $t$, the number of units of the European currency needed to buy one USD. Source of annual exchange rate data: Matthew Shane, US Department of Agriculture.

From Table 2, the clean float prediction is refuted, the managed float viewpoint supported. The table presents the situation for the biggest three, Italy, France, Germany, and the entire 12 who entered the EURO in 1999. Volatilities are

\footnotetext{
${ }^{24}$ In the Greek crisis, the US Federal Reserve also revived swaps with the central banks of the UK, Canada and Japan.

${ }^{25}$ In these accords, Japan, unwisely and irrationally according to Mundell [79] and McKinnon [80] was pressured by the transatlantic alliance to massively appreciate the yen.
} 
about twice as high in the purer clean float decade. Though not depicted, the remainder of the 12 who formed the Euro likewise suffered volatilities in the 1980s almost double those of the 1970s, of the 1990s and in this millennium.

This evidence hints that dirtier floats would have softened the worldwide exchange rate jars from the US giving massive tax cuts and sharply increasing its military expenditures in the early 1980s when the other major currencies were being fiscally conservative. It hints at what might have happened if Italy, France, Germany - and above all the US - had pursued managed floats in the 1980s. It hints that it need not have happened that European countries suffered over that decade a halving then doubling of the value of their currencies vis-à-vis the US dollar. Ours is one interpretation of the shocking 1980s. i.e. the exchange rate shocks would have been less marked but for adoption of both the US and the predecessors of the European Central Bank of especially clean floating for the first half of the 1980s. It hints at Japan having been wise when it sought a stably evolving exchange rate with its key trading partner, and at China being wise in seeking this also, as proposed e.g. in [81, 82].

The reverse interpretation of the shocking 1980s however can be offered - e.g. that the shocks would have been twice or ten times as big were it not for the rather clean float policies, and that the exchange rate changes would have been far smaller had only all the floats been completely clean. Let us start with two unreasonable - but widespread - grounds for querying our interpretation.

\section{OBSTACLES IN PROGRESSING WITH ALGEBRA AND FIELD DATA}

\subsection{Reverse Interpretations}

An alternative interpretation to ours of Part 9 can be drawn using a purchasing power parity model of exchange rates and price determination holding on a quarterly basis. On this model, the European currencies halved then doubled in value against the US dollar in the 1980s because European prices relative to those in the US, doubled and then halved. These exchange rate convulsions caused by the relative price convulsions, would have been even worse but for the clean float policies of both countries keeping relative prices from convulsing even more. But the model's pivotal implication for this era, namely the convulsion of transatlantic relative prices, did not happen. i.e. such a reverse interpretation to ours is falsified by a simple fact.

The same simple fact, namely that European prices relative to those in the US, did not double and then halve in the $1980 \mathrm{~s}$, falsifies another suggestion. This is the suggestion that there was no greater exchange rate instability in the decade of the 1980s if one uses "real" instead of nominal exchange rates. It is also useful to mention, that "real" exchange rates are heuristics - shortcuts that ignore the multiplicity of prices moving divergently. All theorising and econometrics involves abstractions, i.e. heuristics, shortcuts. The heuristics of "real" exchange rates at times mislead trade theorists and the IMF in their exchange rate advice, generating sectoral output effects that are the reverse to those intended $[4-7,10,11]$. Being humans, we have to use shortcuts in the evaluation stage of making decisions, including decisions on what we conclude would be the impact of an exchange rate on an economy. SKAT, the Stages of Knowledge Ahead Theory, allows us to notice that we economists do not maximise as expected utility assumes. SKAT offers us the opportunity to start modeling economic agents as they are, non-maximisers, who can benefit from admitting that they use heuristics as this aids open-ness to when the evidence points to changing the heuristics changing our models and estimation techniques.

Grounds for querying our interpretation of Table 2 that cannot be excluded by how relative transatlantic prices in the early relative to the later 1980 s, fall into three classes.

1 Did we correctly classify the exchange rate regime in each epoque?

2 Is our conclusion robust when we failed to keep other causal factors constant?

3 Is our conclusion robust when we failed to model the micro-foundations of the economies?

\subsection{The Regime Classification}

The clean managed spectrum is multidimensional and thus opens the scope for disagreement on how to weight the diverse components. In addition central bank policy is rarely completely transparent and there are documented instances of policy differing substantially from what is claimed [83]. Further central bankers have been coy about the degree of dirtiness of their floats for multiple reasons, including concern of fanning speculation, concern at admitting their failures, concern about other central banks and governments disagreeing with their actions.

Another problem is that practices diverge because of official sector learning and forgetting with each change in top personnel and each new constellation of external events. This learning and forgetting has resulted in many regime changes in nearly every currency area, and in dramatic changes in what the official sector does. The situation is too complex for evident overall systematic learning by all participants however. We have illustrated the difficulties with key players ${ }^{26}$ - central bankers and their economist advisers - in preceding parts of this paper, and in Appendix 7.

In summary, getting a superior regime classification of matched periods when both transatlantic partners were adequately clean, and other periods when both were adequately managed, so as to discern the difference in impact on exchange rate stability, might not turn out to exist. It could transpire when we complete the analysis, that the only era of a really close match was both clean from 1982 to

\footnotetext{
${ }^{26}$ The situation is also difficult when we get to the minor participants in the exchange rate process - those in the private sector importing, exporting goods and capital, and even less direct participants such as those bargaining over wages that affect inter-country competitiveness. Investigations reveal highly idiosyncratic techniques employed in the decision making procedures of each group, and quite a concentration of power rendering individual personalities and their general group dynamics of importance.
} 
1984. That single clean float match, without a matched managed float era, would not suffice to enable us to infer anything about whether clean or managed floats better stabilise the exchange rate.

\subsection{Other Things Equal}

Suppose we did get matched periods for both regimes after our subtler regime classification. We would still feel that the results (whichever way round they turned out) are questionable. This is because we have ignored other causes like the exchange rates of other currency areas and shocks peculiar to each epoch. As regards, shocks, the 1970s decade included the aftermath of the worldwide grain crop failures of 1969-70, and the two OPEC rises of the 1970s. The 1980s coped with President Reagan's fiscal spurt and its aftermath. The 1990s began with the exchange rate crises of northern Europe and ended with those of eastern Europe and south east Asia. This millennium had the shock of the ending of the US decade of private sector expansion. We might wish moreover to list other shocks, to classify them by sorts, demand, supply expenditure switching, aggregate expenditure changing and so forth - in case these sorts have differential impacts on exchange rate stability.

Suppose we succeed in doing this - mastering all the classification difficulties as regards the relative importance of other currency areas and shock types. We would then need to consider lags, as not all these effects of regime, of other currencies and shocks impact within a day. To have enough degrees of freedom, we would by now require a vast data set given how many other currencies there are in the world, and the multiplicity of shock types. But given that some of the lags demonstrably exceed a year, we have only 36 years after the demise of Bretton Woods, and thus lack the data on this count alone. We would need to do some approximations cutting out what we guess are less important causes to do any empirical estimation.

\subsection{The Micro-Foundations}

Our conclusion might also be questioned as being too aggregate, lacking specifics on the market structure. Unlike some other exchange rate conclusions, e.g. those based on [84] we have ignored the differentiated nature of the products that characterize this inter-country trade. We have left unanalysed the input and output market structures and how these evolved over time. It might for instance matter that the US economy was less oligopolistic than the European market both as regards real sector firms and financial intermediaries, and transatlantic cultural differences in agent's objectives might also matter.

It might also matter how these differences have evolved over the post Bretton Woods era. As regards financial intermediaries for instance, oligopolistic power has been accentuated via mergers and, in some areas, European takeovers (e.g. of virtually the entire US reinsurance business). Objectives of the key figures in the official sectors changes with reallocations of duties and personnel changeovers and unanticipated events. Should they be modeled via an aspiration-adaptation model such as [85] or what? Again, in the private sector, is its behaviour captured as a mix of two sorts of firms as regards international capital and goods flows, one sort prone to hedge their imports, and the other sort prone to speculate as in [86] or how? This raises the general questions of:

1. goal differences amongst agents;

2. differences amongst agents in beliefs on what attains their goals, and

3. group dynamics arising out of 1) and 2) plus changes in the persons holding key posts.

\subsection{An Algebraic SKAT Model?}

It might seem natural to develop an algebraic model of the exchange rate determination process to overcome the numerous legitimate queries of our interpretation of the field evidence in Table 2. It might seem that the combination of the SKAT umbrella theory and the specifics of exchange rate determination delineated in Part 8 offer the golden opportunity for finally discovering all those "fundamentals" that have eluded us economists over the entire post Bretton Woods era. It might even seem that out of it we can predict exchange rates reasonable periods ahead.

A moment's thought however indicates that attaining a tractable algebraic SKAT model in the genre of Part 8 would be an interesting challenge. Consider the matter of modeling how cooperation within a country's official sector, and between a pair of official sectors, change over time. Consider the matter of including how this is influenced by personality changes in the (often) three branches of each country's official sector, and their associated group dynamics.

Consider what would be involved in the above compared to the difficulties already encountered in our current exchange rate models. Current models typically have two currencies - i.e. the issue of third currency areas is ignored or one small country. Firms, where modeled, tend to be identical to households, and do not hedge or speculate, i.e. there are no domestic or international financial intermediaries. Alternatively, firms are implicitly perfectly competitive and comprise only two sorts, informed and uninformed. Alternatively, the current model has a market structure for labour inputs and market output. In both cases firms/households (contrary to fact) have typically identical univariate objective for which maximisation is feasible to specify and done. These simplifications seem needed for tractability. In summary, SKAT algebraic modeling is worthwhile but awesome in the tractability issues from the need to limit the number of causal factors.

Likewise econometric estimation is worthwhile, but involves even greater difficulties. To get the required constancy it needs numerous data points for every causal factor with responses to that cause held constant. As shown in Appendix 7, there is a freedom of degrees problem even were all data available. The 35 years plus that have elapsed since the end of Bretton Woods is too short to get enough episodes with the needed matched exchange rate regimes across currency areas, since official sector heads, who manage these regimes, keep trying to learn and improve. They episodically make different responses, as they notice something amiss, or because it is a new person at the top, 
yielding an overall pattern of learning and forgetting lacking the constancies required for robust econometric estimates of exchange rate regime effects on exchange rates.

\section{THE SCOPE FOR A LABORATORY EXPERI- MENT}

A fresh insight can be a laboratory experiment. The laboratory experiment avoids virtually all the above questionings of our interpretation of the field data. It also goes a long way toward avoiding the tractability issues for theory, and the constancy over time requirements of using field data for estimation. It can specify the markets for inputs, outputs and the exchange rate. It can avoid external currencies that obviously impact, but are infeasible to incorporate in either algebraic models or empirical estimates. It can allow firms to engage in both real and financial international transactions without rendering the model and its associated estimation too cumbersome. It can specify the lag before agents can revise their decisions, and the number of changes that there will be in knowledge ahead that matter to agents, i.e. for how many periods ahead, unknown exchange rate changes can affect attainment of objectives. It can also specify the objectives of each agent with associated monetary rewards for attainment of that set of objectives. And unlike all other forms of theoretical plus empirical investigation, it can leave those agents free to decide how they will seek to attain those goals. It avoids the falsified maximising assumptions underlying most theory and estimation techniques.

Readers may however feel disconcerted at thinking that laboratory findings can shed light on the real economy, especially when in the form of a direct comparison of field and laboratory exchange rate volatilities. It is worth considering therefore how we see other contributions shedding light. This allows us to see that we make just such direct comparisons in our traditional analysis. This allows us to see that the comparisons process is not different in kind from our other sources of knowledge, each has shortcomings, none is the Holy Grail, but each may shed light. We need to be careful that we do not discard experimental evidence, when the identical sort of criticism can be leveled at our standard uses of theory and field data.

In this regard, every paper potentially contributes to our accumulated evidence on whether a clean or a managed float ushers in more stable exchange rates. Each bit of accumulated evidence may support one viewpoint or the other. Or it may support neither, in this case hinting either at the need for more data, or for more complicated viewpoints (theories) on what keeps and exchange rate stable.

Each empirical study, whether employing qualitative or quantitative methods adds evidence. This empirical evidence can never be theory free. Empirical work invokes theories of the market structure, of agent motivations, ways of neutralizing other factors that we could not hold constant, and of rendering interdependent cross sectional or time series data free of their serial correlation, heteroscedasticity and many other features that bedevil using them for estimation and hypothesis testing. Despite all these additional assumptions invoked, empirical work affords us additional evidence not gleanable from armchair theorizing.
Simulations can be of an empirical genre. They are an empirical genre if they insert into theoretical models, parameters and lags obtained from empirical sources such as other econometric or input output studies. Sometimes the empirical component is tenuous and the predictions ensuing implausible. This can occur due to a failure to consider issues such as whether the variables are seasonally adjusted or unadjusted. Failure to do so can yield bad output - some very disturbing simulation results - as uncovered in the critique offered in [87] of the FRB-MIT-PENN model of the US economy.

Again, simulations that are not transparently documented on when parameters are simply assumed, result in bad policy advice, including unwarranted complacency on world population growth. Thus in the case of the agricultural sector of the ORANI 1979 general equilibrium model of the Australian economy of [88], the aggregate supply elasticity was for decades set at 40 and maybe still is. An elasticity of 40 somewhat accords with popular trade models that assume infinite supply elasticity of exports, and most of this sector's output is exported. But it is a parameter value for which there is zero empirical support. Australia has essentially no scope to expand her aggregate agricultural output, only scope to switch under price incentives, from one agricultural item to another. That this parameter is contrary to all known about Australian agricultural production however has not been transparent to world-wide users of the model. It has resulted in CGE models around the world misconstruing the implications of population growth - misconstruing that the growth will be supplied by a massive expansion in Australian food output to feed the world [89].

Both the FRB-MIT-PENN model of the US economy and the Orani model of the Australian economy have some parameters and lags informed by empirical evidence, by econometrics and input-output data. When combined with macro-financial-international modules, such simulations yield exchange rate predictions that stem from a mix of assumed and empirically grounded relations.

Other exchange rate simulation models by contrast spring entirely from armchair theorizing. None of the lags and none of the parameters have an empirical base. Such simulations are of a purely theoretical genre of evidence.

Yet even such purely theoretical simulations are deemed to potentially contribute evidence. This is the justification for their production and dissemination. The potential of purely theoretical work contributing is that we warrant the assumptions sufficiently good approximations to reality, and recognise that in all modeling we must abstract, i.e. merely approximate reality. If not, we give no role to theory contributing to our knowledge base [90].

Thus in purely theoretical modeling, both sides can and do construct models which they see as evidence for their viewpoint of how exchange rates operate. Inevitably, these stem from their conflicting assessments of what assumptions yield good approximations of the workings of exchange rate markets. For tractability, nearly all theoretical models ignore the multiplicity of agents. They rarely contain an official sector comprising more than one decision maker. They rarely model firms involved in goods and capital flows explicitly. 
They rarely combine different sorts of markets (e.g. competitive and oligopolistic) even though stylised facts suggest this. In terms of decision making types, there tend to be a most two, e.g. one so called rational and one so-called noisy, and so forth. All such simplifications are required for keeping the theory tractable.

Further, as already mentioned at the start of Part 5, there are grounds for being very cautious as to whether anyone has reached first base in theoretical modeling of the actual exchange rate. As shown in the remainder of that part, one reason for this failure is the use of standard theories. These, when applied consistently, exclude nearly all the segments of the outcome flow that matter for the economic agents.

\section{OUR LABORATORY DESIGN}

Our laboratory experiment, inclusive of instructions to participants, is in [91]. It seeks to capture key features of corporatist union-influenced continental Europe and thus to aid particularly in examining exchange rate determination effects from a continental European perspective. Output prices are determined in a Cournot market with a limited number of firms, while imported materials prices are competitively determined, and wages set via centralized bargaining between an employer and an employee representative. We examine the effects of a managed float in which central banks automatically intervene to support the exchange rate target, varying the degree of transparency in the manner described at the beginning of section 12.e.). Central bank intervention limits are described in section 12.b.).

\subsection{A Complex Setting}

The world is complex so that conclusions drawn from simplified set-ups may miss effects, and this matter is especially important when the study concerns uncertainty, since uncertainty itself generates complexities. Our design is a compromise between the complexity of reality, and other constraints, including the number of seats in our laboratory, and the maximum time for which we keep participants in a session (one day). To our knowledge it is the most complex experiment performed in an economics laboratory other than two others. One is Tietz' KRESKO macro experiment wherein bargaining between the employer association team, the union team, and the central bank team determined about 200 hundred macro variables [92] in a set-up that permitted equilibrium growth solutions. The other is Becker and Selten's SINTO market [93] wherein firms had to choose their range of products, their advertising, investment, and price for every product, taking into account how closeness in quality and price might influence demand, and how demand might be growing over time. Exceedingly complex experiments have been conducted in psychology laboratories on economic decision making, e.g. [94, 95].

To grapple with real world uncertainty costs, we sought as complex a design as was teachable to advanced economics students for them to play it within a day, and also theoretically analysable with a game theoretic benchmark. While lacking numerous aspects of real world complexity, it is arguably overall closer to reality than any of our current batch of theoretical and econometric models of exchange rate determination. This of course is a tricky judgment to make since reality has so many aspects, and we do not take the view that in every single aspect, there is not one model ever constructed that captures that single aspect better (missing out altogether on numerous others), only that over the entire set of aspects, it could be argued that ours captures more of these in a more adequate manner.

\subsection{A Game Theoretical Result}

Our set-up is too complex to have a discernible standard game theoretic solution. This is despite its being a gross simplification of real world exchange rate markets. It is so simplistic it even has purchasing power parity exchange rates in its equilibrium. This theoretical result points to the uselessness of applying either decision theoretic or game theoretic equilibrium notions to exchange rate determination. In order to nevertheless provide economists accustomed to equilibrium benchmarks with one, Reinhard Selten has constructed (specially for our set-up) a new more realistic game theoretic equilibrium construct to use, that of an incomplete equilibrium, in which players do not consider branches that could not yield superior payoffs. Our experimental dynamic game has many incomplete equilibria, but with the help of plausible selection criteria, a unique incomplete equilibrium for it can be singled out as the solution.

\subsection{A Concrete Set-Up}

We make the context concrete to all participants, given the evidence that context affects decisions. Our set-up has two countries, each with its own currency, symmetric in every respect, and thus suggestive of France and Germany that are of approximately equal economic size, in the days before a currency union was considered. In each country there is: 1 government, 1 central bank, 1 union representative, 1 employer representative, 5 firms who buy local and imported materials produced under competitive conditions (and thus made by a vast number of firms not represented by players in our laboratory). These imported materials are used in fixed proportions to produce a homogenous final good sold in a Cournot market, ${ }^{27}$ with nominal demand set by the government. On these real flows, see Fig. (3).

As regards the financial side of real production, firms buy their imports on credit, and must pay for them only next period. They face fixed costs, must produce at least a minimum amount, and face a capacity constraint on the maximum that they can produce. They act as their own financial intermediaries in any hedging or speculating that they do in the current period, prior to its exchange rate being determined, and thus face uncertainty concerning both the current and the future exchange rate. Firm importing and hedging/speculative activity helps determine the exchange rate whenever the two central banks conflict on their exchange rate goals.

\footnotetext{
${ }^{27}$ Experimental studies reveal that symmetric Cournot oligopolies with five or more participants have difficulty attaining systematic collusion, lack of which, broadly speaking characterises corporatist EURO bloc production. The EUC has been helpful in reducing the corporatist, collusive character of Europe over the past decades.
} 


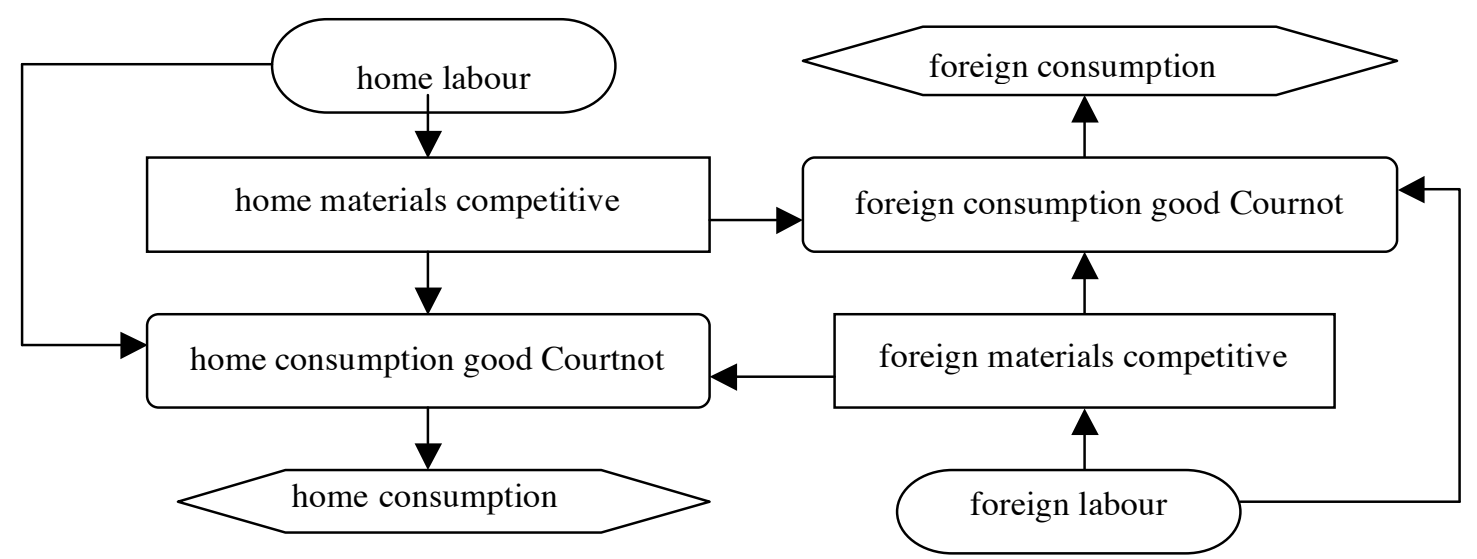

Fig. (3). Commodity Flows

\subsection{Central Bank Intervention}

In the absence of conflict between the two central banks, they set the exchange rate, having complete power to do so, as in all real world countries, via the scope to print their own currency to use for intervention or to organize currency swaps, as the two means of doing this. In the event of a conflict between the exchange rate aims of the two central banks, the amounts of each country's central bank intervention to attain its exchange rate target depends on its import or exports price. It automatically intervenes up to a set proportion, $\varsigma_{2}$, of its export price in the form of selling its own currency, if seeking to depreciate its currency against the wishes of the other central bank, (termed a high aim conflict). It automatically intervenes up to a set proportion, $\varsigma_{1}$, of its import price in the form of buying the foreign currency, if seeking to appreciate its currency against the wishes of the other central bank (termed a low aim conflict). Since countries have more limited scope to intervene in an effort to appreciate against the wishes of other central banks (this requiring foreign reserves), than in an effort to depreciate (this requiring them only to produce more of their own currency), $\varsigma_{2}>\varsigma_{1}$. The actual exchange rate ensuing in these conflict situations is the ratio of offers made by both firms and central banks of each currency as long as this ratio is between the exchange rate aims of the two central banks. Otherwise, since the two central banks cooperate if it lies outside the exchange rate aim of either, it is that of the nearest of these two exchange rate aims.

\subsection{Official Sector Tasks and Instruments}

In addition to the government setting nominal expenditure, the official sector, in the form of its central bank, sets its interest rate and announces its price and exchange rate aim, Table 3. Thus between its government and central bank, a country's official sector has four instruments of macro-management. In having only four instruments, it is, as in real life, under-instrumented for meeting goals. In having the official sector short on instruments, we offer reasonable scope for the popular view to be demonstrated that adding an exchange rate change instrument helps macro-management.

\section{Table 3. Official Sector Objectives}

\begin{tabular}{|c|c|}
\hline \multicolumn{2}{|c|}{ Variables } \\
\hline$q$ & actual price of the home country consumption good \\
\hline$p_{+}$ & next period's target price of consumption good \\
\hline$p$ & current period's target price of consumption good \\
\hline$e$ & $\begin{array}{l}\text { exchange rate, the number of unit of home currency needed to } \\
\text { buy one unit of foreign currency and thus as } e \text { rises, the home } \\
\text { currency depreciates }\end{array}$ \\
\hline$m$ & actual price of home materials in home currency \\
\hline$m^{*}$ & actual price of foreign materials in foreign currency \\
\hline$r$ & interest factor $(1+$ the marginal interest rate $)$ \\
\hline$f$ & exchange rate aim \\
\hline$B$ & $\begin{array}{l}\text { official sector (government and central bank) objective } \\
\text { function }\end{array}$ \\
\hline$L$ & actual employment \\
\hline \multicolumn{2}{|c|}{ Parameters } \\
\hline$r_{0}$ & ideal interest rate, set at 0.05 \\
\hline$L_{\mathrm{a}}$ & minimal acceptable employment, set at 600 \\
\hline$L_{\mathrm{b}}$ & maximum acceptable employment, set at 720 \\
\hline & $\begin{array}{l}\text { weight parameters, } i=1 \ldots 5 \text {. The } b_{\mathrm{i}} \text { are positive constants, set } \\
\text { respectively as } 6,6,3,3,1,0.02 \text { and } 0.01\end{array}$ \\
\hline \multicolumn{2}{|c|}{ Official Sector Objective function } \\
\hline & ${ }_{0}-b_{1}\left(\frac{p_{+}}{p}-1\right)^{2}-b_{2}\left(\frac{q}{p}-1\right)^{2}-b_{3}\left(r-r_{0}\right)^{2}-b_{4}\left(\frac{m}{e m^{*}}-1\right)^{2}$ \\
\hline
\end{tabular}

From Table 3, it can be seen that the official sector has seven objectives: 1 , keeping prices steady; 2 , meeting its price target; 3, keeping its ideal interest rate; 4 , maintaining its ideal level of competitiveness in its cost structure relative to the other country; 5 , meeting its exchange rate target (a goal absent in the one currency case; 6 , avoiding unduly low employment; 7, avoiding unduly high employment. This latter goal is less important than underemployment, and accordingly is given less weight in the overall objective 
function. Although the decisions on instruments were allotted (as in most countries) either to the government or the central bank, the payoff was joint: both work for the national good, with penalties for the official sector deviating from each of its goals.

\subsection{Exchange Rate Targeting and Shocks}

From Table 3, in the two currency case, central banks operate managed floats. As in the 1961 Mundell model, they can target (manipulate) exchange rates so as to re-equilibrate the economy after shocks. But we shed fresh light on the issue by dropping the assumption of there either only ever being one shock ever, or else (in models that extend Mundell), a set of shocks produced by a random generator and in each case external to the system, as it were from outer space. In such Mundellian plus randomly generated shocks models, the central bank knows perfectly the source of the shocks, and exactly where the new equilibrium is, since it has exact statistical distributions of the future. We replace these false assumptions about shocks and knowledge of the new equilibrium in our laboratory experiment, having instead all shocks generated by the domestic official and private sectors in the two countries. Thus in our laboratory set-up central banks and governments can be as fallible and error-prone as has been the Bank of England in its exchange rate policy according to [96-98]. In our laboratory set-up, firms as in real life can attempt to make a profit out of exchange rate dealings if they think that one country's central bank has adopted an untenable position as regards its joint choice of exchange rate aim and interest rate relative to the other central bank. Being also fallible, in our laboratory set-up, if firms misjudge the situation, they may lose funds on a grand scale (like Long Term Capital Management), or on a small scale (like some British universities with overseas campuses). Out of this mix of varied fallible moves by members of the private and public sectors in the two countries, our experiment offers a fresh perspective on whether central banks really are able to use the extra instrument of the exchange rate to improve macroeconomic management, to restore equilibrium.

\subsection{The Private Sector}

Each official sector announces to all in each country its decisions on aggregate nominal expenditure, on the interest rate and its target price for next period. In one treatment each official sector also announces its exchange rate target to all. This might lead to a moderation of exchange rate moves - to the exchange rate staying more toward the middle of the range between the two central bank goals. This could happen as often the interest rate incentive to shift funds will conflict with exchange rate incentive indicated by the official sectors generating either smaller private capital flows or two way counterbalancing flows.

In another less transparent treatment, exchange rate goal information is shared only with the other country's official sector. Here for the firms, the interest rate incentive is unconstrained by exchange rate information from the official sector. Thus private sector capital flows might more often tend to push the exchange rate largely toward the extreme of one central bank's goal, and this might in turn accentuate exchange rate instability.

After each official sector has set its four instruments, and made public knowledge all or three of these, private sector decisions commence. First, in each country, the union and employer representative bargain over nominal wages. The union representative's payoff is real wages measured as nominal wages divided by the announced official sector target price, while that of the employer representative, is a share of total real profits as measured by expenditure deflated total nominal profits. If after the set time allowed of 10 minutes, an agreement had not been reached, there was strike, with both negotiators receiving zero pay, a government set wage, and firms subject to a lower maximum production level and a cut in nominal demand relative to that announced by the government.

Once the wage rate (from bargaining or a strike) was announced for both countries, firms decided on output and on the amounts of a currency (home or foreign) to borrow in order to offer on the foreign exchange market in order to either hedge or speculate. The currency market then operated, and set the period's exchange rate, followed by the consumer market, determining the consumer price, followed by firms paying for last period's imported materials, and profits flowing to the firm's owners.

\subsection{Rounds with Interdependencies, Independent Sessions}

A round is the above sequence of decisions and their outcomes played by both the official and private sectors. A round was played by the same participants 20 times, with a lunch break, typically after the $8^{\text {th }}$ round. The first round was preceded by an hour's instruction. The participants were economics students at Bonn University who had passed two or more years of economics, ranging in skill from those in their third year of undergraduate economics up to doctoral candidates. There were six sessions run on 6 different days in 2003 with the exchange rate aims of the two central banks announced to all. An additional three sessions run in 2005, with the exchange rate aims known only to the two central banks. Each of the 9 sessions contained different participants.

By the end of the associated set of experiments, we have almost exhausted our available pool of different willing participants. The sessions were typically on Saturdays, since few participants were available for an entire Monday to Friday weekday. No session had to be abandoned on account of participants becoming bored or too depressed at their earnings prospects to continue for the whole day. Indeed, especially doctoral students often reported how interesting was the experience, and how instructive in macrointernational finance. Many participants asked for permission to repeat but were refused. Participants were paid in proportion to their task achievement. Appendix 8 gives the details of how many EURO each participant received for each level of attainment. Participants' earnings varied markedly depending on the session and role. They typically earned between the norm and double the hourly rate students 
in Bonn obtain in outside casual employment, but some virtually none, and many others more than fourfold the normal rate.

Our nine independent sessions each of 20 periods means that we have a huge advantage over field data with its time series and cross sectional interdependencies. Our field data stem from a single world and a single history, rendering it tricky, to say the least, to decode the effects of the shocks of the $1970 \mathrm{~s}$, the $1980 \mathrm{~s}$, the $1990 \mathrm{~s}$ and this millennium. In particular, how do we answer from field data alone that key counterfactual of how would exchange rates have moved in the 1980s under no shocks or smaller or different shocks and a managed float policy? The laboratory offers us a fresh handle. We have nine independent economic histories of the managed float, with each with different players, and thus differing propensities to generate shocks, and all our shocks caused by people - as have been nearly all our field shocks. We have 9 independent economic histories to aid us in assessing exchange rate regimes.

\subsection{The Round: Its Real World Duration Counterpart}

\subsubsection{The Multiple Actual Decision Frequencies Simplified to a Single One, a Year}

In actuality, some types of decisions are made at a far higher frequency than are other decisions. To capture a reasonable proportion the actual differential frequencies requires a highly disaggregate input-output structure identifying the differential production lags of different items used in the production process from bread for sandwiches to steel for mines, from coins in the till, to long term credit, from temporary workers to tenured staff, and so forth. These frequencies however render the modeling so complex, that even in input output studies, differential frequencies are virtually never investigated or modeled. In virtually all theorising and most empirical work, there are not even multiple input-output layers, and even where present, no allowance for differential frequencies of decisions. Our setup, whilst having two input-output tiers, likewise suffers the shortcoming of setting the frequency of all types of decisions to be identical. We made this compromise with an eye to keeping the game playable as regards participants' understanding and their time needed to make each decision, within a single day when 20 rounds are involved.

Setting all decision frequencies as in our laboratory setup to be identical has the massive advantage over field empirical data that we avoid all the implicit aggregation assumptions about why the differential frequencies assumed away do not bias the results - implicit since the actual aggregations are too complex to readily start considering. It however sets another question: how does one of our periods relate to actual time flows? We designed it as an approximation to each period being a year.

Our reasoning leading to each period denoting a year started with a lower bound on the duration of each period being investigated via our laboratory technique. We did not wish to model events in time intervals shorter than six months. Shorter durations have limited relevance for the normative issue of exchange regime being investigated for two reasons. First, fluctuations in exchange rates that roughly iron out in a shorter time span have only a modest impact on international trade in goods and services. It is longer lasting adverse changes in the exchange rate that damage international trade. Not surprisingly, most exchange rate studies of the impact of exchange volatility on trade find a minimal effect - not surprisingly since these virtually all use data where the individual observations concern daily, weekly, monthly or quarterly data - not data of a long enough length to be relevant to most trade decisions.

Second, shorter term self-reversing changes in domestic economic activity and relative prices, a government's macroeconomic policy smoothes with automatic stabilizers. Of then, frequencies in excess of six months, what is a rough approximation of the lags and their associated flow durations in setting exchange rates that led us to select the year as the benchmark duration, and design the set-up to very approximately mirror this? In taking a year, our thinking stemmed from the evidence described in the following section.

\subsubsection{Actual Average Decision Frequencies in Trade}

Production varies with a) demand and b) relative prices. The frequencies of actual changes in some components of demand and of relative prices are at least daily. But firms do not respond so rapidly. There is a dearth of information on the actual lags. Sources for value-added in the Australian manufacturing sector over the period 1950-1980 are [4.5.6]. At that time the estimated average lag of production behind demand was a quarter, and behind relative price changes, five to six quarters. ${ }^{28}$

Lack of data prevented estimating the additional lag of payments, and thus approximately, the foreign exchange market impact, behind changes in production. However nearly all international trade in goods and services is on credit, and the credit to settlement date some two months longer than on domestic transactions, and, while like all credit settlements with a lag sensitive to the business cycle, very roughly in the order of a four month lag from receipt of the imports. This suggests average lags of about two quarters before changes in demand causing changes in goods and services flows to impact on the exchange rate. It hints at an average lag of six to seven quarters before changes in relative prices causing changes in goods and services flows to impact on the exchange rate.

The average of these two markedly different frequencies depends on the variation in trade and goods flows arising from changes in demand compared to those arising from changes in relative prices. Variance in demand is for many countries marked compared to that of changes in

\footnotetext{
${ }^{28}$ With computerised accounting, and a higher share of the labour force in part-time jobs in some countries (most notably Australia who now leads the world in its proportion of part-time jobs), the average lag in response to demand may have reduced. The lag in response to relative prices however is unlikely to shorten much since responses to relative prices typically requires complex changes in production techniques, and thus only made at annual board meetings and after enough time has elapsed to feel confident that the relative price changes are not temporary bubbles.
} 
domestically determined relative prices, but tiny compared to that from internationally determined relative prices, namely those for commodities (oil, coal, iron ore, agricultural and pastoral products determined in the international market, and so forth), and coming through the role of exchange rate changes altering import and export prices. It thus seems not unreasonable to postulate that the average lag for the two when computed via their variances may be around 5 quarters.

\subsubsection{Actual Average Decision Frequencies in Capital Flows}

The other components of private sector demand for a country's exchange rate stem from its capital flows. These comprise ones with an extremely short average lag and others with a very long average lag. Hot money and some portfolio investment respond in less than a day to alterations in relative interest rate and exchange rates, though there continue to be responses. Direct investment by contrast has typical lags of years between considering an opportunity and deciding on the terms and amount to invest, and then lags of many months, or even years after the deal is finally clinched, before all the capital flows have occurred, both because of the time required to raise the requisite capital, ${ }^{29}$ and the typical decision to undertake the direct investment in a sequence of stages with each stage up to two years apart. The volatility of long-term investment is substantial, ${ }^{30}$ but that of hot money is legendary. Splits of capital flows into these two components are tricky, and indeed the capital flows themselves even for many developed countries are subject to errors of the order of magnitude of $20 \%$.

There is a presupposition that short term flows are more volatile than at least some long term forms like foreign direct investment, e.g. [99]. But the authors have been unable to locate a corroborating study. They have instead located studies indicating comparable or even greater instability in long term capital flows compared to short term ones. Eg Fleissig [100] found the US long-term capital account to be the culprit in that country's contribution to the international severity of the 1930s Great Depression since long term US capital investment abroad shrank dramatically in 1927, 1928 and 1929, while short term flows remained constant. Claessens, Dooley and Warner [101] study a range of developed and developing countries with data from the early 1970 s to the early 1990s. They found that long term flows were often as volatile as short term flows, that it takes as long for a shock to die out in the case of the long term flows as with the short term ones, each with lags of around 16 quarters, and that the long term flows are as least as unpredictable. Singh [102] offers a range of reasons for anticipating long term capital flows to be as volatile as short

\footnotetext{
${ }^{29}$ In this respect, consider for instance the delays in 2001 that cost Germany's Telecom dearly in cobbering together its EURO funds to transfer for the purchase of US Wireless after all terms of the purchase were finalized. These coincided with an unanticipated drop in the EURO, attributed in the media to a set of massive EURO direct investments (from France and Germany), all in the form of takeovers of US firms. In turn, most of these takeovers were deals clinched prior to the breaking of the US bubble.

${ }^{30}$ See preceding footnote for a reported instance of thousands of billions of cycle-sensitive direct investment.
}

term ones. We thus have taken as a working hypothesis that both short and long flows are equally volatile.

When both short and long term capital flows tend to have like autocorrelation properties, it is not too crucial to estimate the shares of short and long term capital flows. The data in [101] reveal no average difference, but big differences between countries, e.g. the UK was almost exclusively long term for their data period but Germany with at least $10 \%$ more in short term flows. The statistical results reported in [101] point to an average lag of between two and four quarters, depending on whether one looks at their half life estimates or their autocorrelation estimates. Splitting the difference, the average lag discernible from their statistical analysis might be three quarters.

Taking a simple average of our rough estimates of the trade and capital flows average lags, we take our periods as years. We thus use annual exchange rate data in comparing our experimental results on exchange rate volatilities under the set-up of a very managed automatic intervention institution that includes the goal of maintaining international competitiveness with actual exchange rate volatilities.

\section{EXPERIMENTAL RESULTS}

\subsection{Equilibrium Not Maintained}

In every session, participants began their first round with equilibrium choices. In no session did participants maintain the equilibrium exchange rate, even though at that point there had been no shock. Nor did any session ever return to equilibrium even though in every session 20 rounds were played. There was moreover zero evidence that any player realized that they were in equilibrium in making their decisions in the first round. This set of results conflicts with the presumption that economic agents make choices that result in equilibrium. It conflicts with the standard economists' presumption that exchange rate changes are equilibrating - are restoring equilibrium.

\subsection{No Learning}

There were no effects that suggest systematic learning to predict the exchange rate over the 20 periods played. This parallels the actual lack of learning in the complex world of floating exchange rates from 1970 to date. See Appendix 7. Economists have yet to learn to predict the exchange rate better than a random walk in each of the next two years. Likewise in the laboratory, our firms failed to predict for the next and the following round, the exchange rate changes that were wrought by their own actions in conjunction with official sectors [86].

With no evidence of learning in our complex laboratory set-up designed to mirror real world complexity, we therefore report and analyse here simply the average exchange rate volatility of each session (Table 4).

\subsection{Transparency in Central Bank Aims Reduces Volatility}

It can be seen in Table 4 that for those laboratory sessions with a less public exchange rate aim, the average volatility is 
Table 4. Laboratory Exchange Rate Volatilities with two Currencies and Trading Blocs

\begin{tabular}{|c|c|c|c|c|c|c|c|}
\hline \multicolumn{1}{|c|}{ Six Sessions with Public Exchange Rate Aim } \\
\hline \hline Session & 1 & 2 & 3 & 4 & 5 & 6 & Overall \\
\hline Average per period & .085 & 0.024 & 0.033 & 0.017 & 0.039 & 0.030 & .038 \\
\hline
\end{tabular}

\begin{tabular}{|c|c|c|c|c|}
\hline \multicolumn{1}{|c|}{ Three Sessions with Exchange Rate Aims only Known to Other Central Bank } \\
\hline \hline Session & 7 & 8 & 9 & $0 v e r a l l$ \\
\hline Average per period & .057 & .21 & .07 & .112 \\
\hline
\end{tabular}

The exchange rate volatilities were symmetrised to avoid discrepancies between percentages being affected by which way the exchange rate is expressed, and thus by whether the former or later exchange rate is higher. The symmetrisation was done by taking the average of the modal absolute percentage increments $\left|e_{t}-e_{t-1}\right| / e_{t-1}$ and $\left|e_{t}-e_{t-1}\right| / e_{t}$. This average in turn simplifies to $0.5^{*} \mid\left(e_{t-1} / e_{t}-e_{t} / \mathrm{e}_{t-1} \mid\right.$, where $e_{t}$ is the exchange rate in period $t$, the number of units of home currency needed to buy one unit of foreign currency

over double that of the other six sessions. On a non-parametric one-tailed Mann-Whitney U-test, this is a significant difference at the $5 \%$ level. This is suggestive of more transparent managed floats aiding in exchange rate stabilization.

\subsection{Managed Floats have Lower Volatility than Clean Floats}

Let us now compare the above laboratory volatilities for a two currencies and trading blocs case, with those experienced between two actual sets of currencies and trading blocs - the EURO bloc and the US - since the demise of Bretton Woods, summarised in Table 2, Part 9 above. For the 1970s, 1990s and for the current millennium, the exchange rate volatilities of the EURO countries with the US are in the vicinity of double that of the laboratory managed float with open exchange rate aims. For the 1980s, the hey-day of clean floating, these countries suffered exchange rate volatilities in the vicinity of four-fold the volatility of the those in the laboratory experiment with their managed floats. The other epoques were in between clean and exchange-rate-stabilising managed floats given the documented flip-flop changes in regime policies of official sectors depending on whether they perceive it as more urgent to be seen to be exclusively concerned about curbing inflation or attending to other needs of the economy.

The laboratory results thus hint that when countries engage in a managed float with a transparent exchange rate aim and respond to the normal panoply of domestic objectives as regards prices, interest rates, over and under employment and international competitiveness in determining their exchange rate aims, the resultant exchange rates are likely to be far more stable than when many central banks follow price/inflation clean float policies as has been the case in the last few decades. The results suggest that if central banks have a basket of goals, including international competitiveness, an exchange rate aim, and active intervention, exchange rates would likely have been far steadier. If however the exchange rate aim is not transparent, the laboratory results thus suggest that the managed float is significantly worse in stabilizing the exchange rate than when this is public knowledge to all players - not merely a secret among central banks.

\subsection{Dispersion, Outliers}

Many of us would see an influence for instance for the particular personality of a central banker or a particular president, in actual exchange rate determinations, e.g. a role for the personalities of US Fed Chairmen Paul Volcker and Alan Greenspan, and for the US President Ronald Reagan. Our theories have difficulty (understatement) in allowing for these differences and when unanticipated, their shock impacts. We need such information about such deviations from central tendency. We live in only one world with one history. Bad luck for the world if we economists advocate policy "reforms" that on average work, but lack escape routes, should reality prove not to be close to the average, but an outlier on the wrong side.

The dispersion of possible outcomes can pinpoint dangers in exchange rate policies. Attention to dispersion as a separate factor from any indirect impact dispersion may have on the expected utility of the outcomes is fundamental for economists avoiding proffering dangerous foolish choices as regards exchange rate regime. Such attention to dispersion is consistent with SKAT, the Stages of Knowledge Ahead Theory since it incorporates the stages during which the future exchange rate is unknown, Part 7 above. SKAT enables the economist to notice country risk premia caused by a country's exchange rate fluctuating wildly as discussed in the case of Australia, Appendix 3. By contrast, economists employing EUT, axiomatised expected utility theory, have a blind eye to risk premia, and actually praise the Australian official sector for these wild swing, e.g. [1. p28]. This blind eye to the financial and emotional secondary satisfactions of safety springs from the fact that EUT requires decisionmakers to evaluate each possible exchange rate outcome as if it were certain to occur, Part 5 above. This is preposterous and irrational. ${ }^{31}$

\footnotetext{
${ }^{31}$ That EUT precludes policy makers from doing any tradeoff between safety and the mean was brought to the attention of the English speaking EUT community in $[103,104]$ noting the implausible coincidences required for the EUT decisionmaker to choose as if doing a mean-safety tradeoff. Allais mentioned this matter earlier in an Econometrica article in 1953, but in French, therefore somewhat inaccessible to many. In fact, even stronger restrictions (more remarkable coincidences) than those identified by Borch and Feldstein are needed for an EUT decisionmaker to accidentally choose as if doing a mean-safety tradeoff [105-109].
} 
More generally, EUT's sole focus on expectation has contributed to economists' failing to include a safety assessment when advocating policy changes. Instead they typically advocate policy changes based on point estimates of the expected impact or direction of impact. This point estimate is their proxy for the expected utility of the policy change. The upshot is that many recommended policy changes by EUT trained economists are dangerous as they have a high likelihood of turning out later in actuality to be much worse than their proxy for the expected utility of the policy change.

In appraising economic policies therefore, we ought to make better use of our standard errors and confidence intervals in our statistical estimates than EUT training of economists has elicited. Standard errors and confidence intervals enable us to focus on dispersion and to recognise dangers in some policies, and which alternative policies are safer. SKAT affords us a consistent means of including these safety considerations in our appraisals of exchange rate regimes. SKAT allows us to steer policy makers towards choice of a safer exchange rate regime, since SKAT avoids the EUT mistake that regarding a policy maker as irrational for not choosing whichever policy has the highest expectation of utility. SKAT allows the policy maker to recognize that it can be reasonable to reject a dangerous policy that has somewhat higher expected primary satisfactions, and choose instead another with increased secondary satisfactions from more safety in the pre-outcome period (one with a lower dispersion of the primary satisfactions reaped from the outcomes).

Experiments offer us yet another angle on dispersion, on outliers, on idiosyncracies arising from individuals and their group dynamics. Virtually nothing else is different in these independent sessions, only the individuals and their group dynamics. Laboratory experiments are a handle on whether the outliers are close to the average, or far away, i.e. on how dangerous are our "reforms" due to unpredictable and unmodeled idiosyncracies.

Let us therefore, with the umbrella of SKAT, look at the average volatility in each of the nine individual laboratory sessions. Their dispersion is a measure of our degree of uncertainty in drawing policy conclusions due to the role of individual differences or group dynamics. In one of the six sessions where the exchange rate aim was transparent, known to all agents, the average volatility was high, namely that listed as session 1 in Table 4 above. This indicates that transparency on the exchange rate aim aids, but does not guarantee, the roughly halving of the volatility found to be associated with rendering the float transparent in its dirtiness.

Again, in one of the three sessions with a non-transparent aim, the one that we labeled as session 8 in Table 4 , there is an outlier so high as to indicate that under a non-transparent managed float, the volatility might even be as pronounced as under a clean float. Transparency is often hard to attain, for reasons discussed earlier. This outlier reveals the dangers of attempting stable exchange rates, instead of eliminating the danger by shifting to a single world money.
Furthermore, the laboratory evidence presented in [61] indicates that the more stable the exchange rates, the better is macro management, especially as regards international competitiveness, and that currency union furnishes the best macroeconomic management. In short, contrary to the presumption in [1, p28], the extra degree of freedom of official sectors being able to alter the exchange rate does not assist in macro-management. The presumption that the extra degree of freedom aids an economy's return to equilibrium in the wake of shocks is a presumption that rests on simplifications to yield tractable algebraic modelling. These ignore real world complexity for members of the official sector and the fact revealed by our experimental set-up, that nobody can compute what might be the game theoretic equilibrium or even discern if there is one, not scientists with arm-chair years to ponder possible solutions, and certainly not members of the official sector needing to respond quickly to hourly reports on external events.

\section{CONCLUSIONS}

The paper has traced the failure of economists to predict exchange rate changes to the degree needed for good macroeconomic management and avoiding needless firm bankruptcy. There have been now over 35 years of efforts to get these predictions since the breakdown of Bretton Woods. Official sectors, academic economists and private agents alike have failed to predict the extreme damage of world wide exchange rate liquidity shocks that twice occurred, nor the other two such shocks that would have occurred but for rapid action of Alan Greenspan and the US Federal Reserve Board.

After the extreme exchange rate liquidity shock of the 1980s, official sectors of the key currencies did recognize the value of managed floats to stabilize exchange rates, and implemented exchange rate coordination via the Plaza Accord of 1985 and the Louvre Accord of 1987. But within seven years, numerous official sectors had reverted to the clean float policy. This is an astonishing speed of forgetting, even allowing for rapid personnel turnover, and the famously short sighted perspective of current day economists who have eliminated both history of thought and economic history from their teaching syllabi.

Again, in 1998, Alan Greenspan then chair of the US Federal Reserve, ensured an orderly collapse of the giant hedge fund Long Term Capital Management after it grossly mispredicted the USD-ruble exchange rate. Without this rescue Greenspan feared a 1929 style depression being unleashed from the dislocation of international financial markets. It is astounding that the needed rescue did not revive awareness of the necessity for stable exchange rates and adequate government regulation for stable financial markets. Instead the very next year the reverse occurred. There was increasing clean float rhetoric and in the US the repeal of the 1930s Glass Steagall act, a repeal that enabled US commercial banks to directly precipitate an exchange rate liquidity crisis via their mortgage securitisation sales to 
foreign commercial bank counterparties and others. Indeed this is precisely what ensued.

The blindness of official sectors to the impending exchange rate liquidity shock in 2006, like their rapid forgetting of the 1980s exchange rate liquidity shock, lies in cognitive dissonance. Members of official sectors have been educated within the epistemically atemporal maximizing lens of expected utility neoclassical theory wherein there can be no exchange rate liquidity shocks. They lack a coherent framework for analyzing what actually happened in the early 1980s, as also for what has happened 2006-2009. Members of official sectors need an alternative coherent intellectual framework that matches the broad contours of reality in its abstractions and faces the reality of non-maximising but within a coherent framework, potentially sensible decisionmaking procedures of human beings.

To be coherent, the alternative framework must abandon epistemically atemporal expected utility theory that ignores the essence of risk, namely the anticipated changes in knowledge ahead. SKAT affords such a framework. Within the umbrella of SKAT, our central bank conflict cooperation model of exchange rate determination allows understanding. Understanding does not mean prediction of exchange rate changes. Understanding includes understanding that exchange rates are inherently unpredictable because of the personalities of key deciders and their interpersonal dynamics, the multiple sorts of agents who impact on exchange rates, the multiplicity of exchange rates, evolving resources, and other factors inducing complexity. Our field and laboratory evidence demonstrate the illusion of chasing a new generation of exchange rate models that will predict well enough to justify keeping multiple currencies.

Prior to the advent early last century of numerous national central banks advised by often unintentionally nationalistic economists, the gold standard held. Adherence to the gold standard was freely attempted by private sector unregulated banks, and in more advanced countries generally succeeded in being adhered to without exchange rate liquidity shocks of exits from that system $[62,110]$.

After Bretton Woods' collapse, a half-way house to a single world currency, namely cooperatively managed floats, recurred in the mid 1980s, but had largely evaporated by 1990. A return to cooperatively managed floats is advocated in [13] and in the United Nations Conference on Trade and Development's Trade and Development Report 2010 [111]. These would be a marked improvement over the current situation of episodic extreme uncertainty and massive liquidity risks. But our field evidence underscores the dangers of transiency in these cooperative exchange rate arrangements.

Our laboratory evidence on outliers underscores other dangers from variable exchange rates, namely the scope for personality constellations in key posts to generate marked exchange rate instability. Further our laboratory evidence points to the superiority of macro-management without the voluntary additional layers of complexity inherent even in managed floats. Even with managed floats, official sectors and private agents have to deal with the unnecessary additional layer of complexity of being unable to predict the exchange rate, and suffering episodic exchange rate liquidity shocks.

Unlike many other demand and supply shocks in the system, exchange rate shocks are entirely avoidable through renunciation of national currencies. Our joint field and laboratory evidence thus indicate the benefits of hard pegs, dollarisation or currency unions as advocated in $[8,112-$ 115]. Our field evidence on the fragility of cooperatively managed floats, and our laboratory evidence on outliers in the typical situation in which central bank exchange rate aims are non-transparent, make the case for going further and forging a single world money. This has been advocated in $[46,66,78,79,116,117]$, and in the wake of the east European and Asian currency crises, by a wide range of policy makers, financiers and journalists. ${ }^{32}$ Advocacy of such a single world currency is an interpretation of a speech given on the $23^{\text {rd }}$ March 2009 by Zhou Xiaochuan, head of the People's Bank of China. A single world currency was directly advocated by the Russian President Dmitry Medvedev when he held up in July 2009 at the G8 meeting a coin displaying the words "United Future World Currency" as reported in eg Lyubov [120]. A single world currency is also raised as a possibility in [121], by the International Monetary Fund (IMF)'s Strategy, Policy and Review Department under Dagupta et al on Reserve Accumulation and International Monetary Stability of 2010.

Such a single world currency could arise by modifying the IMF's Special Drawing Rights beyond the extent proposed subsequently by the Russian and Chinese governments, see e.g. [120,122], and backed transitorily by Geithner, see e.g. [123]. It could moreover be ushered in, as was the EURO, without exchange rate liquidity shocks jolting the pre-existing exchange rates. There are practical difficulties in its institution and thus more genuine integration of capital markets of different countries [124, 125]. But these are not insuperable, and on the basis of our field and laboratory evidence, the benefits would be pronounced.

\section{ATTRIBUTIONS AND ACKNOWLEDGEMENTS}

The paper is written by Robin Pope based on her hypotheses of the causes and effects of the post Bretton Woods exchange rate evolution and interpretation of the open economy literature, with valued input on most drafts from Reinhard Selten. The experimental set-up is based on an model constructed by Robin Pope and Reinhard Selten. The separation of the government from the central bank was advised by Jürgen von Hagen. The programming, wording of instructions, running the experiments, and requested calculations were provided by Johannes Kaiser, Sebastian Kube, Kai Ebenrett and Sebastian Goerg. We thank: for comments on earlier drafts and presentations Jane Binner, Richard Cooper, Kjell Hausken, Adrian Pagan, Stuart Payne, the late Norman Roberts, Barkley Rosser, the late Arnold

\footnotetext{
${ }^{32}$ See e.g. the eminent proponents listed a decade later in [118]. Those crises even roused The Economist to contemplate a single world currency [119].
} 
Zellner and two very helpful anonymous referees of this journal; for background information Tom Courchene, Brian Easton, Jeffrey Frankel, Peter Kenen, Bill Klein, Ed Nell, Nathan Sheets, Jürgen von Hagen, Kerstin Wandschneider, John Williamson, Massimo Warglien, Jing Wang, members of Harvard's Kennedy School Lunches for Development Policy, Richmond University's Macroeconomics Lunches, the New School University's Economics department seminar series, and attendees at Aston University's Measurement Error Conference; for research assistance, Angela Meyer, Andreas Orland, Jing Pan, Ali Zaidi and Shiraz Ahmed; and for funding, the German National Science Foundation and the Center for European Integration Studies.

\section{APPENDIX 1}

\section{The Clean Float}

\section{Its Domestic Price Orientation}

Under Friedman's notion of a clean float, the country's central bank gears its monetary management exclusively to the domestic price level - or as a surrogate, inflation, an arguably inferior goal [126]. Under more eclectic notions, the clean float concept extends to all closed economy goals of an economy. Initially clean float purists completely ignored any potential impact monetary policy might have on the exchange rate, e.g. [127]. But the domestic price level indirectly influences, and is influenced by, the exchange rate - because of the export and import effects of international capital, trade and services flows that impinge on domestic prices and employment [128].

\section{Its Evolution to Partial Open Economy Modelling}

The closed economy perspective of clean floaters is changing toward a recognition of some open economy aspects. Some now consider the effects that the exchange rate can have on domestic goals in what is termed the new normative macroeconomic research agenda [129]. Today also some clean floaters give exchange rate interventions and associated announcements an instrumental role in attaining price and inflationary goals via signaling. E.g. the German central bank explained some exchange rate interventions in defence of the DM as signaling - according to Sam Cross's notes for a US Federal Reserve System meeting [130]. Such signaling is also modeled in so-called rational expectations models of clean floating, e.g. [131]. The country's exchange rate is not a goal in its own right. But it has become for some clean floaters, a recognized instrument for attaining the domestic price/inflation goal.

The moderate clean floater relegates to a footnote - and the extreme clean floater wholesale ignores - collateral exchange rate damage caused to its own or other economies as regards output, debt and asset transfers. It might be thought therefore that clean floating is only considered viable for small countries without close connections to any other small country as regards trade and capital flows. Under such conditions it could be that the damage that they may wreak on other countries is minor enough to be ignored. However, as will be seen in sections 1.3 and 1.4 below, clean floating is advocated for big countries, and in the fifteen years prior to the eruption of the global financial crisis in 2007, was being practised by many of them.

\section{Evolution in the Implementation of Clean Floats}

The details of how to implement a clean float have varied over time. This mirrors monetarists' altered understanding of the impact of money on prices and inflation, and on whether fine-tuning is feasible. There was a fine tuning era of interest rate targeting in the 1960s to early 1970s. Then there was a non-fine tuning era of money stock targeting over roughly the next 15 years. This followed Milton Friedman's 1969 discovery that the lags before money impacts on prices are long and variable, and essentially under a two-year horizon unpredictable. Subsequently, with no new information that money has more predictable and shorter lags, an era has arisen in which the clean float operates via interest rate changes as indicated by price changes. This new clean float era arose from difficulties in relating the money base to price changes, and difficulties in giving a long-term stability rule for interest rate changes equivalent to the Friedman money stock rule. There are indications of clean floaters reverting from a focus on interest rates for fighting inflation to Friedman's call to focus only on the money stock, e.g. [132]. The new clean float era has progressively taken longer perspectives about how interest rates influence prices/inflation. In practical policy and reports of success, a vagueness has entered via words such as the "underlying" inflation rate. Discretion is advised on just when to implement anti-inflationary measures so as to limit deficient output and unemployment, e.g. Bernanke's 2003 talk in praise of best practice explicit inflation targeting. A discretionary lull in fighting potential inflation is practiced by clean float inflation fighters such as Sandra Pianolto during the "unwelcome disinflation" of 2009. This board member promises that the US Federal Reserve will "shift ... making sure that higher inflation does not develop ... [as i]t's the job of the central bank to keep inflation under control", while avoiding indicating when this shift will take place [133]. Other clean floaters contend that an explicit target number for inflation would mitigate deflation dangers by incentivising the central bank to keep monetary policy adequately expansionary during severe downturns [134].

\section{Advocates for Exchange Rate Stability}

The IMF is prominent among today's clean float advocates for attaining exchange rate stability. E.g. the IMF applauded Indonesia in 1997 for deciding to quit exchange rate interventions and to adopt clean floating, announcing that this will aid its financial stability. It also advised Poland to simultaneously: 1) make a clean float (in the form of its central bank pursuing exclusively a domestic inflation target); and 2) prepare for admission to the EURO. Admission to the EURO requires that the Polish currency stay within an extremely narrow band for an extended period, much narrower than that historically experienced by Poland. The IMF thus saw such clean floats as ultra stabilizing of exchange rates in the late 1990s despite the fact that the East Asian exchange rate liquidity shock of 1997 came in the wake of these economies adopting cleaner floats 
and less regulated markets than before. Others also advocate clean floats as a means of keeping exchange rates more stable, e.g. for developing countries [135, 136], and for the US itself [137]. In a similar vein [138] deems that developing and east European countries that quit targeting the exchange rate and floated cleanly enhanced monetary policy credibility and financial stability.

\section{Control of Monetary Policy}

Monetary policy can be split between two or three official sectors. In Australia for instance, there is such a three way split, with the central bank, the treasury and the government all with a say. In the US there is a two-way split, with the Treasury in charge of exchange rate interventions, and the Federal Reserve Board in charge of the key discount rate. Actual monetary policy can thus conform to a clean float without it being a goal of all authorities involved in official monetary policy.

\section{Practice of a Clean Float}

The clean float perspective sprang from a desire to get the government out of exchange rate management, and indeed to generally minimise its role and role back interfering financial legislation enacted in the aftermath of the 1929 US stock market crash and ensuing great depression. Its heyday was thus the heyday of the pro free market movement. This had gathered strength from the late 1970s, and was implemented in most developed countries, including in their exchange rate policies, to a very marked degree in the early 1980 s by the major currencies on both sides of the Atlantic. The mixture of rolling back or unofficial disregarding of the financial regulations enacted in the 1930s was a progressive procedure only halted with the onset of the 2007-9 global financial crisis [13, 139-141].

The pre-eminent example of an extreme clean float is that of Paul Volcker's period as chairman of the US Board of Governors that coincided with Donald Regan, a dedicated clean floater, being at the helm for the US Treasury, a post that Donald Regan held until 1985. Volcker is widely regarded as the saviour of the US economy from the high inflation of the mid 1970s through his persistent control of the US monetary base. Paul Volcker moreover personally avows that he pursued an anti-inflationary goal singlemindedly. Some of his critics felt that he should have compromised to alleviate unemployment in the US. Other critics felt that he should have compromised to mitigate the damage imposed on other countries. See e.g. his retrospective interviews on his Chairmanship of the US Federal Reserve System made to the US Public Broadcasting System [142].

\section{Volcker's Undesired Clean Float}

This does not however mean that Paul Volcker sees floating exchange rates as a blessing. It does not even mean that he wanted a clean float. In an interview with Perry Mehrling [67], Volcker elaborates that he would have liked the US to swallow its national pride and depreciate in 1970 (to cope with its Vietnam War expenditures) instead of breaking up the Bretton Woods Agreement. He further reports that when he instituted a tight monetary policy to seek to curb domestic inflation, it was not his intention that this translated into a clean float policy. He wished the US Treasury to permit the Federal Reserve Board to engage in foreign exchange intervention in order to (partially or wholly) sterilise the exchange rate effects of his monetary policy by selling US dollars on the foreign exchange rate market. The US Treasury however, for years declined to authorise the Federal Reserve Board to intervene in the exchange rate market.

Thus although in the public broadcast, Volcker reports that he felt that in a world of floats, his tight monetary policy was the best for the US and the rest of the world, this is not the full story. He would have preferred to keep Bretton Woods, and as a second best, to have a managed float - only the failure to attain a managed float prior to 1985 he blames on an uncooperative US Treasury. In 1985, the pragmatic James Baker exchanged posts with Donald Regan and US monetary policy departed from its clean float stance, a departure already sought on the other side of the Atlantic.

Volcker's position that US Treasury intervention could have kept the US dollar steady in the early 1980s while he pursued an ultra tight domestic money policy and Reagan pursued an ultra expansionary fiscal policy is dubious. It is especially dubious given that across the Atlantic primarily contractionary fiscal policies were pursued, hints at a perspective in which domestic activity and prices are independent of the country's open economy linkages. ${ }^{33}$ Volcker therefore seems in this regard to be a product of an imperfect transition from closed economy prescriptions to open economy prescriptions.

However, it might be argued that Volcker has progressed further in seeking to reconcile open economy linkages with domestic monetary policy than many academic advocates of clean floats. He indicates inadequate theoretical back-up from his academic colleagues and Federal Reserve Board research staff on this topic. Thus in a panel discussing exchange rates at the American Economic Association meetings in New Orleans, 2001, he constantly challenged his academic co-panelists, all enthusiastic floaters, to explain what was so good about floats. He reminded them that the associated exchange rate outcomes are unpredictable and thus hard to connect to the academic claims of floats being superior as regards stabilising exchange rates or anything else.

\section{APPENDIX 2}

\section{Dirty and Managed Float Details Dirty Floats}

A policy of having an official sector alter its exchange is in the postworld war era essentially always justified as something beneficial to both affected currency blocs. The

\footnotetext{
${ }^{33}$ It could be derived from attributing a far bigger impact of the foreign component of the domestic monetary base on the exchange rate than has the domestic component of the monetary base, and there is evidence of its being bigger, but so far as the authors know, no estimates of its being the requisite amount bigger, nor of Volcker having employed such estimates.
} 
justification is restoration of equilibrium that is asserted to benefit both parties. A focus on the US current account being in a Meadian disequilibrium deficit underlies the conclusions in [143] that earlier Japan, and today China, should appreciate against the USD. ${ }^{34}$

But most advocates of deliberate official sector changes in exchange rates focus on the domestic unemployment prong of the Meadian concept of joint keeping multiple currencies in order to focus on situations of underemployment in a particular country. ${ }^{35}$ These advocates argue that restoration of full employment and equilibrium can be attained by that country depreciating, or the partner country appreciating. The academic strand of this literature applies Mundell (1961) to particular sorts of shocks in the wake of a rise in domestic unemployment. The US and the EU were strident advocates for Japan appreciating on the unemployment ground into the later 1980s, and have been likewise strident advocates for China to appreciate over most of the last decade and a half.

Countries have however on occasion engaged in a dirty float to avoid importing inflation, e.g. Germany and Australia in the early 1970s, or to partially counteract swings in commodities prices, e.g. Canada and Australia intermittently since World War 2. Praise of dirty floats as giving the country monetary independence to restore or maintain domestic equilibrium with respect to employment or prices include [1, 3, p28].

\section{Managed Floats}

Advocates of managed floating to stabilise exchange rates either dispute the validity of the Meadian pair of equilibrium concepts or else ignore them. Keynes switched from advocating that the UK depreciate by going off gold in the later 1920 s so as to reduce UK unemployment, to advocating stable exchange rates in the later 1930s after witnessing the uncertainty generated by beggar-thyneighbour depreciations of successive countries. In the early 1940s he proposed a world central bank with more powers than the current IMF. Support for managed floats with marked intervention to maintain exchange rate pegs has continued to attract supporters, e.g. [113, 114, 144-146] In a like spirit, Charles Bean, Executive Director and Chief Economist at the Bank of England, in 2001 at the Royal Economic society conference criticized the European Central Bank for not choosing to use its obviously available intervention powers to intervene and stabilize the EURO, Islam (2001).

Into the 1990s, numerous developing countries floated very dirtily to try to stabilise their exchange rates. This is

\footnotetext{
${ }^{34}$ The alternative, non exchange rate procedure for increasing exports above imports is to induce via fiscal policy one's own country to save more and to spend less on domestic consumption and investment. This alternative procedure is moreover reliable. Economists know a good deal more about how to withdraw funds from an economy so as to contract demand and imports than about how to contract imports and stimulate exports by altering the exchange rates. Indeed depreciations can perversely so increase the import bill that the current account worsens.

${ }^{35} \mathrm{On}$ the beggar-thy-neighbour bias in how the Meadian concept of equilibrium is in practice applied by advocates of exchange rate changes, see Appendix 3 and [16].
}

seen as a wise policy given how international debts can become unmanageable after a depreciation [147]. But developing countries sometimes became cleaner under pressure from the IMF and the Washington Consensus to liberalise their capital markets. ${ }^{36}$

Clear-cut examples of countries with very managed floats to stabilise their exchange rates today are Japan and China. Another clear-cut example of a managed float amongst themselves was the decision to seek a European Monetary system in 1979, one that in steps led to 12 European countries joining currencies and adopting the EURO two decades later with a single currency operated under the European Central Bank. In a similar vein other countries have taken the extreme of exchange rate intervention to stabilize exchange rates and eliminated currency differences entirely via government acts of dollarisation or currency unions.

\section{APPENDIX 3}

\section{Beggar-thy-Neighbour Managed Floats via Mundell [46] in1961}

Beggar-thy-neighbour managed floats were commonplace in the 1930s. A country depreciated to seek to solve one's unemployment problem in the hope that this would boost exports and aid import competing industries. Often soon after another country retaliated with a depreciation. In due course countries decided that a preferable exchange rate regime was the Bretton Woods Agreement. Mundell [46] attributes the horrors of the 1930s to the failure to quickly enough make the Bretton Woods agreement and remove floating exchange rates and beggarthy-neighbour competitive depreciations. $\mathrm{He}$ never advocated the managed floats proposed by scientists who refer to his 1961 model. He rightly complains that he distanced himself from them in that article, not merely in his consistent advocacy since of a single world money. He objects to the persistent misinterpretation of his 1961 article by those advocating floating exchange rates. He advocates a single money simply on the grounds that this will reduce transactions costs, e.g. [79].

As Mundell has complained, many use Mundell [46] to ascertain optimal currency areas, indeed it remains the dominant framework for assessing proposed and actual currency unions [8]). All such usages in practice amount to advocating the beggar-thy-neighbour managed floats of the 1930s. To scientists employing Mundell [46] and extensions thereof, this may be surprising. We therefore explain unnoticed features of that model - how its denial of the complexity, uncertainty, and risk experienced in the real world enables this. Later in Part 4 we shall see how in general, not merely in Mundell [46] that denial of complexity, uncertainty and risk seems natural under our

\footnotetext{
${ }^{36}$ Reservations on this pressure have been expressed, e.g. [99, 148]. Another study, while not estimating separately the exchange rate component of the IMF raft of conditions, finds that obtaining IMF help with its attendant conditions, is damaging to an economy, namely [149]. Yet other studies conclude that the impact of exchange rate regime on exchange rate stability is ambiguous or country-specific, e.g. [150].
} 
standard expected utility theory lens, and deflects our attention away from uncertainty effects experienced in real time.

\section{Certainty Despite a Mundell Shock}

In the Mundell (1961) set-up, there is a once for all shock, never to be repeated, and nobody ever expects another shock. i.e. everybody believes in certainty, always did before the shock, and always does after. This, to put it mildly, is a dubious assumption for deciders being even half way rational. But then, often deciders are irrational, or at least myopic and unduly inward looking. For instance, it did take countries in the 1930s a while to discover that other countries would retaliate and that instead of a certain future, exchange rates were exceedingly uncertain and unpredictable.

However, it is dubious to propose that in reality as distinct from theory, a country can use the Mundell [46] solution more than once. A repeat Mundell (1961) solution requires both countries and all those other countries dealing with them to be rather more myopic and non-anticipatory than is the norm. We notice that exchange rate dealers often sharply increase the country risk premium after an unexpected depreciation. The increase in country risk premium can plausibly be interpreted as a realisation that the country's exchange rate is uncertain, something excluded under the Mundell [46] model's reliance on certainty. This in turn excludes repeated use of the Mundell [46]) model within the period before forgetting occurs as regards risk premia, and people get lulled into seeing the future as certain. See $[151,152]$ for evidence on how long is required for such forgetfulness. Yet scientists employing the Mundell [46] model to investigate advantages and disadvantages of a currency union, to the authors' knowledge, fail to comment on this matter. i.e. they fail to take into account that a country could only ever use the exchange rate once - without the model's assumption of certainty becoming altogether implausible, and its implications correspondingly false.

The model's assumption of certainty before and after the single shock moreover excludes all possibilities of anyone being ignorant about the type of shock and its consequences. This assumption of full knowledge about the shock's type and the shock's consequences has misled economists in their analysis and policy advice concerning exchange rate regime as shown below.

\section{Certainty in Attaining Instantly the New Equilibrium}

In Mundell (1961) everybody in both countries understands where, after the shock, is the new equilibrium. Everyone understands that it is good (with rigid nominal wages) for one of the two countries to depreciate to restore the international level of competitiveness after a special sort of shock. Thus there is no scope for retaliation. Everybody agrees that the single never-to-be repeated exchange rate change is beneficial to both countries and will be instantly implemented. There could not be a case of the country that has appreciated protesting that now its wages are too high, and that as a consequence it is suffering unemployment, losses in export markets and in import competing markets.
In this Mundell (1961) world, no country would ever need to risk being accused of beggar-thy-neighbour activity in lobbying another country to appreciate or in itself depreciating. In this Mundell [46] world as in reality, there is an adding up accounting identity. After a shock, each pair of countries recognises and readily agrees whether it is the sort of shock where one country should appreciate, and the other depreciate.

\section{Systematic Bias in Discerning the New Equilibrium}

Let us now contrast this academic exercise - in which the accounting identity holds - with what economists tell an actual country to do in an actual situation. The authors have been unable to identify any country other than Singapore that has a body of economists writing in academic journals or advising the government, seeking to have that country's wage level raised because it is excessively competitive in the international arena. Instead the authors find economists advising virtually every land that their country's unemployment woes arise via too high wages.

The notion that, apart from Singapore, every country has suffered a special sort of shock that might be aided by a depreciation is thus untenable. It violates accounting identities. The fair Mundell [46] model translates in the complexity of the real world into a beggar-thy-neighbour managed float policy. The complexity of the real world generates uncertainty on just where is equilibrium and just what sorts of shocks have occurred.

Thus US economists see a solution to its jobless private sector recovery from China appreciating, and estimate the trade gains from a Renminbi appreciation. They seem quite promising [153]. For its part, China seeks to avoid this appreciation as far as is feasible, given its massive unemployment problems. Economists concerned for poor China, worry that it could follow Japan into long-term recession if it yields substantially to US pressure to appreciate [80]. In practice, therefore, in the murky world where nobody knows where the equilibrium is and has only a vague notion of what sort of shocks have occurred, against his wishes, the model of Mundell (1961) is used as a justification for beggar-thy-neighbour procedures. The econometric exercises conducted in that vast branch of research on optimal currency areas, have served as inadvertent buttresses for anti-social behaviour. In practical policy, this massive branch of econometric literature has not merely been futile. It has been counterproductive in furnishing unwitting support for biased exchange rate interventions in the name of speeding attainment of equilibria. ${ }^{37}$ For further details, see [16].

\section{APPENDIX 4}

Attempts to Deal with Risk Effects Experienced in
Chronological Time within EUT The Coincidence Attempt

Friedman and Savage [45] argued that although the choices made under EUT ignore risk effects experienced in

\footnotetext{
${ }^{37}$ It is thus unsurprising that affordable nationalism rather than criteria in Mundell [46] come closer to correlating with exits from currency unions [159].
} 
chronological time, the decisions made under EUT could coincide with those proposed by the older asset theory (in which variance and other measures of dispersion, i.e. of risk, were included) - if EUT choosers have concave "as if certain" utility functions. They criticised Marschak for not recognising this. Marschak [154] accepted the criticism, converted to EUT and introduced the following confusing new terminology, taken up in the Arrow-Pratt measures. i.e. what is called "risk attitude" in EUT is whether:

(i) the as if certain utility function is linear, so called "risk neutral",

(ii) the as if certain utility function is concave, so called "risk averse", and

(iii) the as if certain utility function is convex, so called "risk loving".

But by the late 1950s it had become more widely known that Friedman and Savage and Marschak were mistaken about the scope of EUT to coincide in its decisions with mean variance models. Borch [103] and Feldstein [104] reported that the conditions required for EUT to coincide with a mean variance model are rarely satisfied. Further Schneeweiß [105,106,107,108,109] proved that the conditions in Borch and Feldstein were too weak to attain the coincidence.

Another restriction that does enable EUT to coincide with mean variance models was discovered later. This is if choices concern assets - and the asset market is complete and perfect. But even the financial section of the asset market is far from perfect and far from complete. The coincidence route thus fails to enable EUT to accidentally choose as would a reasonable theory of choice under risk that includes risk effects experienced in chronological time.

\section{The Elaborated Outcomes Attempt}

Other ways for EUT to include risk effects experienced in chronological time date back to the early 1950s. One is the proposal to specify the decision situation more fully or to redefine or elaborate the outcomes, e.g. Samuelson [44], Markowitz [155,156] and Caplin and Leahy [147]. But these elaborations destroy EUT's axiomatic base and preclude the derivation of its representation theorem in the usual sense [51].

\section{The Temporal EUT Attempt}

Initially the concern had been about omitted emotional chronological time effects that EUT omits. But by the mid $1950 \mathrm{~s}$, it was realised that there were also financial chronological time risk effects that EUT omits. Initially proposals were along the lines of specifying the decision situation more fully. But in due course - since planning involves multiple time periods and an outcome flow with multiple outcome segments - it was realised that atemporal EUT could not include these. Work commenced on constructing new temporal EUT axioms, e.g. Kreps and Porteus [157], Caplin and Leahy [156] and Klibanoff and Oxdenoren [158]. The problem is that an EUT axiomatisation has to derive the mechanical atemporal probability weighting rule. In order to derive it a compound gamble (a mixing) axiom is required of the sort that assumes that the decisionmaker faces simultaneously at the point of choice: a) a non-degenerate probability distribution, i.e. a risky future, and b) a degenerate probability distribution, i.e. a certain future. This precludes getting a non-contradictory set of axioms detailing the actual delays that precede resolution of risk, and blurs the distinction between real time risk effects that must enter the satisfactions (utility) mapping with atemporal aggregation effects that are outside time [50, 54]. Such a false simultaneity postulate precludes understanding the distinction between the chooser's anticipated possible cause effect chains of an act, and how the chooser integrates (aggregates) these into a single value of an act. This is because in temporal EUT it generates a situation in which sequential risks are assumed to be sequential - with positive delays before being resolved) and at the same time assumed to be non-sequential - with delays of a zero duration before being resolved.

\section{APPENDIX 5}

\section{SKAT}

Unlike temporal EUT, SKAT allows for the consistent recognition and inclusion of all secondary satisfactions (i.e. all real time risk-based and certainty-based effects) plus inclusion of all primary satisfactions. It was partly to help alleviate confusions on what satisfactions atemporal EUT excludes, and temporal EUT inadequately and inconsistently analyses, that Pope [160] introduced the terminology of secondary satisfactions, and its counterpart, primary satisfactions. Note that whether real time certainty-based effects, i.e. secondary satisfactions stemming from certainty - full knowledge ahead - are excluded from (atemporal) EUT, depends on the version of EUT. These certainty effects (e.g. satisfaction from complete safety, security) are excluded under the Ramsey version of EUT, but are included (along with illusory ones) under the Friedman and Savage version of EUT [161].

To delineate the essence of SKAT, we take an example within the simple temporal model of $[47,48,49,50]$. In this simple model, all risk is completely resolved at a future time $k$ that the chooser knows exactly at the time of choice, time $t=0$. The chooser divides his future at $t=0$ into only two periods: period 1 before the risk is resolved, termed the pre-outcome period: and period 2, after the risk is resolved, termed the postoutcome period. In starting SKAT in this appendix only at the point of choice $t=0$, there are therefore only the last two stages of knowledge ahead of Table $\mathbf{1}$ and Fig. (2) in Part 5 above. Let our chooser be a central bank. In the pre-outcome period, as a SKAT decision maker this central banker takes into account $H$ different sorts primary satisfactions, $P_{1 h}, h=1, \ldots H$ and $J$ different sorts of secondary satisfactions $S_{1 j}, j=1, \ldots J$ anticipated in period 1 . He in addition takes into account $M$ different sorts of primary satisfactions $P_{2 m x}, m=1, \ldots M$ and $N$ different sorts of secondary satisfactions $S_{2 n i}, n=1, \ldots \mathrm{N}$ anticipated in period 2, the post-outcome period if outcome segment $x$ occurs. There are $\mathrm{X}$ different mutually exclusive outcome segments in the post-outcome period that may occur when the risk is resolved. Hence $x=1, \ldots X$. In the pre-outcome 
period, since the risk concerning which outcome will occur is yet to be resolved, all satisfactions anticipated are simultaneous (i.e. they are anticipated to occur together as denoted by "and"). By contrast in the post-outcome period, only those satisfactions are anticipated to be simultaneous that pertain to a single possible outcome $x$. The anticipations for different possible outcomes are mutually exclusive, as denoted by “or". See Table A5a.

Table A5a.The Anticipated Satisfactions from Choosing an Alternative

Period 1, the pre-outcome period: all the $\mathrm{H}$ primary and $\mathrm{J}$ secondary satisfactions $P_{11}, \ldots, P_{1 \mathrm{H}}$ and $S_{11}, \ldots, S_{1 \mathrm{~J}}$

Period 2, the post-outcome period: different amounts of the M sorts of primary and $\mathrm{N}$ sorts of secondary satisfactions will pertain for each of the $X$ mutually exclusive outcome segments $P_{21 x}$ and $\ldots P_{2 M x}$ and $S_{21 x}$ and... $S_{2 N x}$, where $x=1, \ldots X$

One needs atemporal aggregation rules for amalgamating all these satisfactions listed in Table A5.a into an overall value of that particular alternative in order in order to assess whether that alternative is good enough (if he is a satisficer), or to compare with those other alternatives in the choice set that he considers worthwhile analysing. Table A5.b provides an example.

Table A5b.Example of a Numerical Aggregation

\begin{tabular}{|c|c|}
\hline \multicolumn{2}{|c|}{ Pre-Outcome Period 1 Total Satisfactions: $\mathrm{V}_{1}=\mathrm{V}_{1 \mathrm{P}}+\mathrm{V}_{1 \mathrm{~S}}$} \\
\hline Primary Simultaneous & Secondary Simultaneous \\
\hline $\mathrm{V}_{1 \mathrm{P}}=\quad \sum_{h=1}^{H} \mathrm{a}_{\mathrm{h}} \mathrm{P}_{1 \mathrm{~h}}$ & $\mathrm{~V}_{1 \mathrm{~S}}=\sum_{j=1}^{J} \mathrm{~b}_{\mathrm{j}} \mathrm{S}_{\mathrm{ij}}$ \\
\hline \multicolumn{2}{|c|}{ Post-Outcome Period 2 Total Satisfactions: $V_{2}=V_{2 P}+V_{2 S}$} \\
\hline $\begin{array}{l}\text { Primary Simultaneous } \\
\text { Under Outcome } x\end{array}$ & $\begin{array}{l}\text { Total Primary: Addition across } \\
\text { Non-Simultaneous } \\
\text { (Mutually Exclusive) Outcomes } x=1, \ldots X\end{array}$ \\
\hline$V_{2 \mathrm{P} m}=\sum_{m=1}^{M} c_{m} P_{2 m i}$ & $\mathrm{~V}_{2 \mathrm{P}}=\sum_{x=1}^{X} p_{i} V_{2 \mathrm{P} i}$ \\
\hline $\begin{array}{l}\text { Secondary Simultaneous } \\
\text { Under Outcome } x\end{array}$ & $\begin{array}{c}\text { Total Secondary: } \\
\text { Non-Simultaneous of } x=1, \ldots X\end{array}$ \\
\hline$V_{2 \mathrm{~S} i}=\sum_{n=1}^{N} d_{n} S_{2 n i}$ & $\mathrm{~V}_{2 \mathrm{~S}}=\sum_{x=1}^{X} p_{i} V_{2 \mathrm{~S} i}$ \\
\hline \multicolumn{2}{|c|}{$\begin{array}{l}\text { Overall Value: } \text { under SKAT: } \mathrm{V}=\mathrm{V}_{1}+\mathrm{V}_{2}=\mathrm{V}_{1 \mathrm{P}}+\mathrm{V}_{1 \mathrm{~S}}+\mathrm{V}_{2 \mathrm{P}}+\mathrm{V}_{2 \mathrm{~S}} \text {; under EUT: } \mathrm{V}=\mathrm{V}_{2 \mathrm{P}} \\
\text { Note: }\end{array}$} \\
\hline \multicolumn{2}{|c|}{$\begin{array}{l}1 \text { EUT excludes } V_{1}=V_{1 P}+V_{1 S} \text { and also excludes } V_{2 S} \text {. The exclusions of these three } \\
\text { sets of satisfactions under EUT can be seen to have nothing to do with the aggregation } \\
\text { rule to use probabilities as the atemporal weights for mutually exclusive outcomes } \\
\text { since this SKAT central bank also weights mutually exclusive alternatives by their } \\
\text { probabilities. }\end{array}$} \\
\hline \multicolumn{2}{|c|}{$\begin{array}{l}2 \text { The aggregation weights for the different primary and secondary satisfactions } \\
\text { simultaneously anticipated in the pre- and post-outcome periods and are respectively } \\
a_{h} \text { and } b_{j .}, c_{m} \text { and } d_{n} \text {. In this example, as in EUT, the aggregation weights for mutually } \\
\text { exclusive anticipated satisfactions are the probabilities of their occurrence } p_{i} \text {, and the } \\
\text { sum of total satisfactions in each of these periods is a simple sum of that period's total } \\
\text { primary plus total secondary satisfactions. The weights are unrealistic since a real } \\
\text { central bank lacks numbers for satisfactions and probabilities and thus has no use for } \\
\text { numerical weights. All aggregation weights are atemporal in any decision theory, } \\
\text { including SKAT and EUT. These weights have nothing to do with anticipated } \\
\text { experiences in chronological future time. }\end{array}$} \\
\hline
\end{tabular}

Unlike in Table A5b the aggregation steps are almost invariably conducted qualitatively. This is because normally the aggregation, like the satisfactions themselves, is of a qualitative form, and follows algorithmic procedures of sequentially considering sources of satisfactions, often with a satisficing component, choosing an alternative when it yields enough satisfaction. It is however, easier to see the fundamental difference between SKAT and EUT via Table A5b. Here we unrealistically impute to our SKAT central bank numerical satisfactions and weights (for linearly separable satisfactions) and a probability to each possible outcome and use of these probabilities as his atemporal weights for aggregating these mutually exclusive outcomes to form its overall value of an alternative. Table A5b thereby highlights the three sets of satisfactions that EUT omits - even in the case of numerical probability weights for the atemporal aggregation of the mutually excusive satisfactions. These three omitted sets are: primary satisfactions in the pre-outcome period, secondary satisfactions in the pre-outcome period, and secondary satisfactions in the post-outcome period.

\section{APPENDIX 6}

\section{Illustrating SKAT}

Here, let us illustrate SKAT with the minimum four epistemic (knowledge) stages that a chooser could encounter after discerning a problem meriting a decision. Let our illustration be France's central bank in July 1993 upon discovery of a speculative attack on the French franc, an attack whose cause remains to this day controversial. We draw on accounts of this historical episode in [162, 163], information kindly furnished by Massimo Warglien on Italy's exchange rate crisis experience the year before, and of the UK exchange rate experience in the preceding year in [164]. Despite using these accounts, our illustration is fictional, partly since it is so exceedingly simplified, and partly since it is designed to illustrate SKAT and general issues in exchange rate determination.

Whiles fictional in its specific details, some general aspects of our account are factual. We shall draw attention to some of these factual general aspects when commenting afterwards on the four stages, and again when presenting our model of exchange rate determination. This illustration helps explain why we have decided to differ so radically from other exchange rate determination models in the following respects.

1 Central bank cooperation or conflict is key to exchange rates.

2 The norm, apart from the early to mid 1980 s, is for central banks to have multiple goals.

3 There is a limited circle of people whose decisions have a major impact on an exchange rate, most of who are in the official sector, and amongst whom are personalities, friendships (or enmities) whose idiosyncracies may be decisive. 
4 The decision process is primarily qualitative, with no resemblance to the maximisations assumed in theoretical derivations of a central bank reaction function.

\section{Stage 1.1}

On facing an unexpected attack on the franc, the Banque must discover available alternatives since it is ignorant of its choice set. Suppose it discovered that it could: raise interest rates; or depreciate at once; or try to ride out the crisis. Then the Banque has had a change in its knowledge ahead. The Bank knows its choice set. It has entered the second part of stage 1, stage 1.2.

\section{Stage 1.2}

Its task now is to evaluate these three alternatives, work out which are safe alternatives (with a single known outcome if chosen), and which risky, with more than one possible outcome, and the details of each alternative - vaguely posed initially. How it makes the more precise, the preliminary step in the evaluation process, stems from its goals.

\section{Its 7 Goals}

First, there is the goal of becoming part of the EURO bloc. The Maastricht Treaty required exchange rates of EU members entering the EURO bloc to keep within a narrow band. A sizable depreciation would breach this treaty requirement. Both key French political parties want France in the EURO, and so for this reason are against much of a depreciation against Germany. Those French firms that have borrowed in DM on the assumption of a pretty steady exchange rate, and will suffer a sizable increase in indebtedness if their trust in the exchange rate's steadiness proves to have been misplaced. The government and the Banque are also against much of a depreciation in order to maintain French pride. France had joined forces with the UK back in 1989 against Germany's central bank's request to be allowed to markedly appreciate against other countries planning to enter the EURO bloc. The national pride of the French in a strong franc and the like desire of the UK to have a strong pound had (under the rules of an earlier treaty) allowed these two countries to stop Germany from undertaking its desired appreciation to cope with the inflationary pressures arising out of the integration of east Germany. Already the UK looked foolish, having in 1992 felt forced to stop defending the pound on the "Black Wednesday" of September 1992, and as a consequence having had to quit being in the formal EURO entry process.

There are the Banque's set of roughly six other goals the matters of 1) prices and inflation low and 2) prices and inflation as forecast, 3) maintaining international competitiveness, 4) keeping interest rates appropriate, 5) keeping employment at a good level, and 6) pleasing the main political parties. At the time of the attack, competitiveness does not indicate a depreciation, and inflation does not indicate an interest rate rise. Indeed the low level of inflation and the sorry state of employment indicates an interest rate drop - and so does the forthcoming election.

\section{The Safe Alternatives of a Big Interest Rate Hike or Depreciation}

The Banque considers alternative a), raising interest rate. It concludes that this would need to be sizable to keep the Franc from depreciating below its EURO entry specified lower band, but if sizable, safe. Ie, a sizable interest rate hike would be guaranteed to avoid the franc going outside the agreed exchange rate band and so guaranteed to keep France in the EMS and thus also essentially without any of the undesirable and disruptive wealth redistribution that would accompany a sizable exchange rate change of depreciating below the treaty agreed lower band limit. The Banque considers the distress to the country of a tight money policy when the country is already in depression and the opposition it would have to shoulder from political parties - especially as elections were nearing, and there is no need for a higher interest rate as regards international competitiveness or inflationary forecasts or targets.

The Banque next considers alternative b), the distress to key political parties of an immediate sizable depreciation. A sizable depreciation would be safe. It would be guaranteed to end the speculative pressure. But it would force France's exit from the EMS, and both the main political parties have endorsed entering the EURO bloc.

\section{The Risky Alternative of Seeking to Ride Out the Crisis}

Finally, the Banque considers its third alternative, seeking to ride out the crisis. It realises that this has no guaranteed outcome. It considers the downside risk. Failure implies a massive loss of taxpayers' funds plunged in the effort of holding the French franc in the EMS band. It considers the costs of failure to be worse than those of the UK when it had failed nearly a year earlier after attempting to ride out its exchange rate crisis and had been forced out of the EMS. It considers that the cost of failure would be similar to those of the Italian central bank that had also about a year earlier tried to ride out a crisis over an even longer period and yet failed. The Banca d'Italia had by the time it failed, lost essentially all the official sector's foreign reserves, had a massive depreciation and exit from the EMS. There were such drastic debt repercussions for the public sector that government had taken $6 \%$ or so of every Italian bank account to bring its public debt back to a manageable level. ${ }^{38}$

The Banque considers the chance of success for itself, considering what differentiates France from the UK and Italian failures. It feels it has a better chance to persuade Erminger, the head of Germany's central bank to intervene enough on its behalf. Erminger sees France as a wellbehaved nation in having a lower inflation rate than Germany itself. He has already twice come to her aid in the

\footnotetext{
${ }^{38}$ The "plunder" just might have been rough justice if bank accounts of the speculators had been swelled by the speculative gains, i.e. falling more heavily on these than those who had not speculated and thus had not such large accounts in the aftermath. This raises an interesting issue of a new instrument, that if it had BIS cooperation and WTO endorsement, might enable governments to differentially tax holders of their currency, e.g. choosing to levy taxes on such holdings only after undesired depreciations of their currencies.
} 
last year in two other speculative attacks, and the German federal government is dedicated to keeping France in the EURO. The Banque also thinks that even if it does not get sufficient cooperation from Germany's central bank to avoid a depreciation below the amount permitted under the Maastricht Treaty, that France is such an important country for Germany to keep in the EMS, that the treaty terms might be softened so that France does not have to forfeit EMS membership. However, getting the treaty terms softened would require time, so that pursuing this option would involve attempting to ride out the crisis. The Banque realises that it could have: 1, huge luck - no depreciation and no need to keep highish interest rates after to deter a fourth speculative attack; or 2, modest luck, with a bit of a depreciation pushing it below the currently permitted EMS band, but that band being widened to keep it in the EMS and this being maintainable with continuing highish interest rates; or a disaster.

Suppose the Banque decided to try to ride the crisis out. This is because it hopes for more cooperation than the German central bank offered the UK and Italy in their crises nearly a year earlier and enough German federal government support to get the treaty changed if need be. i.e. the Banque hopes to get at least the modest luck outcome. ${ }^{39}$ Then the Banque has had a second change in its knowledge ahead. It knows its choice. It has entered stage 2.

\section{Stage 2}

The Banque now waits to learn if it has luck. It does not get enough cooperation from Germany's central bank to avoid a drop in the value of the French franc. But it does get enough cooperation that the drop was not catastrophic and it has the luck of being permitted nevertheless to remain in the process planned to lead into the EURO. This is because its lobbying succeeded in getting the EMS band (within which exchange rates must stay) widened. It is in the modest luck category only, having to maintain highish interest rates despite its recessed economy as speculators did get a bit of a reward, and in this sense have saddled France (because of its modest depreciation) with a modest increment in the country's risk premium. ${ }^{40}$ Then it has had a third change in its knowledge ahead. It knows the final segment of this outcome flow.

\section{Stage 3 and Summary}

The Banque has full knowledge ahead - certainty of the middling success from its decision - and the fallout of some loss of taxpayers' funds and asset redistribution both within France and between France and the rest of the world, plus

\footnotetext{
${ }^{39}$ I.e. the Banque has decided it may have more luck than the Bank of England a year earlier when it had to deal with a speculative attack on the pound, and sought rather than tight money in a severe recession to dare that Germany would avert a depreciation and avert its forced exit the process planned to lead into the EURO. That dare failed as Germany did not offer enough cooperation. The vain attempt to avoid a severe depreciation failed, costing UK taxpayers billions, and the UK exited from its government's desire to stay in the process planned to lead into the EURO.

${ }^{40}$ It could have avoided this by choosing its safe but disagreeable policy especially disagreeable as preceding elections - of a substantial interest rate hike at the beginning of the speculative attack.
}

the fallout of a risk premium to be born into the future of higher interest rates than otherwise for an extended period. Table A6 summarises the four stages through which the Banque passed, progressively having more knowledge ahead, and by stage 3 , certainty - as regards that crisis.

\section{Literature}

For stage 1 there are the satisficing and aspirationadaptation models $[85,165,166]$. There are also critiques of central bankers, arguing that they at times failed to search broadly enough for alternatives, and thus sometimes ended up with a bad decision simply because they failed to notice a good alternative and thus did not include it in the choice set.

For stage 2 there is literature on the difficulties in performing such evaluations [167]. This research allows us to understand the difficulties of economists described in Part 2 trying to evaluate under real world complexity where is equilibrium within a Mundell [46] frame. Nearly all economists conclude that nearly every country in the world would be more in equilibrium with a depreciation, implying that at least half misevaluate. Work on the heuristics used in stage 2 includes [55, 56, 168-171]. In the exchange rate context, work on the heuristics of real exchange rates as a short cut to tracing the effects of the multiple prices in an economy, as discussed in Part 3, show that these real exchange rate heuristics yield conclusions concerning exchange rate effects that, for some countries, are the opposite of the actual effects $[4-6,10,11]$.

There is for stage 3 , literature on secondary satisfactions (on uncertainty effects anticipated to be experienced in chronological time) includes the effects of uncertainty on firms engaged in investment as distinct from production delineated in Keynes [172], as noted in Walsh [52, pp. 56, 62-66], and in effect extended in [47, 48, 161]. In the case of the Banque, the costs of this uncertainty (the negative secondary satisfactions) are the higher than otherwise interest levels and shortage of funds of its stakeholders (through some of them speculating against the French franc).

For stage 4, there is a literature from standard decision models on primary satisfactions. For stage 3 there is also a literature from non-standard decision models that consider secondary satisfactions in the form of risk and uncertainty effects from the legacies of the preceding decision stages. One such legacy of prior risk is disappointment that the previously possible better final outcome segment did not occur [173]. In this regard the Banque will have been disappointed as it had successfully defended two prior attacks without virtually no depreciation, but thankful that the outcome was not more dire.

Another such legacy of prior risk is being fired when others discover in stage 4 that in stage 1 the CEO had chosen the wrong act of rejecting the Norwegian government's offer of what later proved to be the most lucrative north sea oil field [174]. In this respect the Banque did not suffer as much criticism as might have ensued had the depreciation forced it out of the EMS process planned to lead into the EURO.

A third such legacy of prior risk in stage 4 is having to repay more interest because of the risk endured in stage 3 by 
Table A6. The Banque's Four Main Stages of Knowledge Ahead After Encountering a Crisis

\begin{tabular}{|l|l|l|}
\hline $\begin{array}{c}\text { Stage/Period } \\
\text { Outcome Segment }\end{array}$ & \multicolumn{1}{|c|}{ Activity } & Unknown \\
\hline \hline 1.1 Pre-Choice set & Discovering Alternatives & Choice set \\
\hline & $\begin{array}{r}\text { Evaluating Alternatives } \\
\text { a) safe option - raise interest rates; or } \\
1.2 \text { Pre Choice }\end{array}$ & Chosen alternative \\
& $\begin{array}{l}\text { c) } \text { safe option - depreciate and exit the EMS; or } \\
\text { outcomes: 1, failure or; 2, modest luck; or 3 huge luck }\end{array}$ & \\
\hline 2 Pre-outcome* & Waiting to learn its luck with choice of c) & Last Outcome Segment \\
\hline 3 Post-Outcome & Living with modest luck under its choice of c) & Nothing - full knowledge ahead, certainty \\
\hline
\end{tabular}

*Irrelevant, as of zero duration, if the Banque had chosen sure alternative a) or b).

the lender involved a risk premium interest surcharge [48]. In this respect the Banque's stakeholders faced less of an increase in risk premia than if France had been forced to exit he process leading to the EURO. Still the Banque had to shoulder the unpleasant legacy of many of its stakeholders suffering a difficult hike in their non-Franc denominated debt repayments out of this unanticipated and moderately successful speculative attack on the currency - an attack that even with hindsight was puzzling economists afterwards [163]. It knows moreover that it will suffer for an extended period from having to subject its stakeholders to higher than otherwise interest rates to ensure that there will not be another speculative attack.

\section{APPENDIX 7}

\section{Official Sector Learning and Forgetting About Exchange Rate Regimes}

Empirical work requires an exchange rate regime to operate for long enough under one regime, and then for long enough under another, with other important causal factors held constant, or controllable, for us to discern the difference (if any) that the two regimes make to exchange rate stability. For instance, suppose we wanted to measure the effect on exchange rate stability of Volcker's clean float regime vs Greenspan's multiple-goal-influenced exchange rate regime. Then for the US we have around 20 years of data, or somewhat less after we allow for some lags. We have actually far less data, since we need to subtract degrees of freedom for every other causal factor that was operating, and whose values changed over the period, such as various sorts of shocks and gradual predictable structural changes.

We also need to get corresponding data for other countries since an exchange rate involves two currencies. Ie, we need a set of partner currencies, or at least one single partner currency for the US that had exchange rate regimes that changed at roughly the same time. Otherwise we get mixed results from one partner having a clean float and the other not, and our econometric estimation becomes infeasible. Such correspondence held roughly for a few years in the early 1980 s when clean floats were especially widespread.
But by the mid 1980s, most countries had the horror of a roughly halving of currencies against the US dollar in which all their roll-over debts were denominated, and a roughly doubling of world wide interest rates, leading to a fourfold increase in their roll-over international debt, virtually all of which was unhedged and denominated in US dollars. No country, not even any rich one, could escape noticing drastic disadvantages in the clean float policy. As reported in Part 7, Germany switched to a managed float - intervened on the exchange rate market to try to bring down the US dollar, and Margaret Thatcher intervened via a discussion with Ronald Reagan to bring it down.

What this amounts to is that the exchange rate regime keeps changing as the official sector discovers problems with whatever regime it has adopted. This learning causing a regime change thwarts econometric estimation. Econometric estimation needs the regime constant across a pair of countries long enough to estimate the effect of that regime.

It might be thought that this is an isolated instance of being unable to match up regimes in two currencies. It might be thought that we can choose another two decades in the post-Bretton Woods era, or another pair of countries even for the 1980s and since, that offer alternated symmetric regimes for long enough to perform the econometric estimation. Such however is not the case. While there are world-wide trends of learning and forgetting about the disadvantages and advantages of each sort of exchange rate regimes, constellations of factors relating to the particular countries and the personalities involved, create discrepancies in when major regime changes are adopted, and how much there is of change in the actual regime from quarter to quarter.

The mirror image of the reports of central bankers that they face unpredicted and unwanted exchange rate changes, not merely in the early 1970s but today, is that they are ever trying to learn, but not making systematic progress in learning about exchange rate movements. Somewhat similar comments hold as regards the impact of monetary policy on prices, above all in the short to medium term. As Friedman [17] had discovered, the lags are long and variable. His discoveries of these long and variable lags are not something that can be estimated econometrically in the least reliably using quarterly data, the norm in econometric models devised to advise central bankers operating clean floats. 
Econometric estimates require constancy of coefficients for each lag. There has been learning and forgetting over the decades on the length and unreliability of these lags.

All this means that even if we could discover a pair of countries with matched clean float exchange rate regimes sequelled or preceded by matched managed float regimes, how each country implemented each regime would tend to keep on changing, and not changing in a synchronised way. In this regard, it might be no difficulty for econometric estimation if such learning - and its counterpart of individual and institutional forgetting - has a steady pattern as in some theoretical models of $\mathrm{x} \%$ learned and $\mathrm{y} \%$ forgotten per period of some univariate instrument applied to some univariate goal. Such however is false. Official sectors have multiple instruments of monetary and exchange rate policy, multiple objectives of managed floats, and the learning and forgetting is of an episodic nature, with indeed no readily discernible systematic trend toward enhanced knowledge. A world of floating exchange rates renders this too complex for official sectors who hire us economists - mirroring our own failure to master the fundamentals of the exchange rate. Below we trace a couple of episodes of the learning and forgetting of the post Bretton Woods era to underline the daunting task of using econometrics that requires constancy to analyse exchange rate regime effects on exchange rate stability.

Consider intervention techniques. When floats began in the early 1970 s and since, some official sectors deemed that exchange rates were exclusively demand driven and this continued into the 1980s. Australia's deregulation of the exchange rate was orchestrated and administered under such an extreme neo-Keynesian viewpoint!

Others, of the monetary school, thought that any expansion of a country's high powered money base would have like effects on its exchange rate. They thought that selling off some of its domestic debt component to shrink the monetary base would be identical to selling off some of its foreign reserves. That after all is how monetary models depicted it. Any change in the monetary base shrinks domestic money and thus should have a like effect of raising the currency's value. Such neutrality, it was concluded, is far from the case both as regards speed of impact and overall impact. Foreign exchange interventions operate far faster, and arguably more powerfully than do operations on the domestic base. This altered management of both clean and managed floats in some countries. The learning about this however is far from systematic, in part because it has not entered most economists' theoretical and econometric models, so that new generations of advisers arrive at central banks - each generation has a life of high influence of only perhaps five years.

Even where central bankers choosing a managed float decide on intervention, there has been little systematic learning on whether announcing the intervention reduces the needed size of intervention and increases its likelihood of success, or has the reverse effect of engendering dangerous and unmanageable speculative moves. The evidence from academic research remains mixed, but tilted to announcing.
On the part of some central banks, including the US Federal Reserve and the European Central Bank, the trend is to announced, e.g. [175].

But this conclusion, that announced foreign exchange rate interventions are faster and stronger and more reliable than domestic base operations in their impact on the exchange rate, can be interpreted as having a large element of country and time period specificity. This can especially be the case if the operations on the domestic money supply are heralded as being taken without any regard to their exchange rate implications. With such a conjunction, the old-style undifferentiated attention to the monetary base is for instance a feasible interpretation of the exchange rate impact for Australia at the end of 1982, the beginning of 1983, as follows.

Less than a year after floating, Australia prior to an election in the normal electoral fashion, expanded the base, lowering the domestic interest rate immediately but not causing any immediate increase in inflation. Movers on foreign exchange markets asked is this serious, not about to be reversed tomorrow now that the country has moved this year to a float? The Treasurer stated that it will hold, and the exchange rate promptly depreciated $25 \%$ on a trade-weighted basis. The country's risk premium jumped correspondingly.

Some took this as a lesson that Australia ought abandon its clean float policy that could accommodate short term monetary expansions without jeoparidsing its inflation target, and move to a managed float with the exchange rate itself a goal in its own right. Others found no connection of concern or damage between the country's monetary policy and its exchange rate collapse. E.g. the treasurer expressed his pride in the country's new found monetary independence, the prime minister anticipated massive jobs increases from the fortuitous depreciation, and the Treasury employed a quarterly longer term interest rate series in which it detected no jump in the country's risk premium [6]. A few years later, the exchange rate entered the central bank's goal, i.e. the float became officially managed, but since it has exited, i.e. the float is again officially clean. Should this be classified as:

1 switches in the confusion of floats, or

2 learning followed by unlearning in reverting to a cleaner float, or

3 unlearning followed by learning in returning to the cleaner float?

Finally, suppose that we managed to find a pair of countries that for the requisite eras alternated with both having clean then both managed of vice versa and both had identical understandings of how to operate their regimes, could we then empirically estimate that effect? The answer is major qualifications. We would then need to consider the matter of other exchange rates impacting on that pair of currencies. But there are so many of these that we use up all our degrees of freedom including them, leaving none over for empirical estimation unless we make assumptions about which to omit. On which to omit we are left to our own judgment since we lack robust models of exchange rate determination to guide us in this regard. Indeed, the problem 
of third currencies is so tricky and so consumptive of tractability possibilities and degrees of freedom, that few enter theoretical or empirical studies. In these respects too, the laboratory is attractive. It keeps much about the exchange rate regime steady, and excludes entirely the impact of the galaxy of their country currencies. It gives us a fresh insight to complement our empirical work on field data.

\section{APPENDIX 8}

\section{Payoff Conversion Formulae}

The payoffs in the game itself were expressed for each role in Talers for each point one. The conversion of Talers into Euros was monotonic but not proportional. It varied such that each participant had an identical payoff if all played according to the incomplete game theoretic equilibrium, and was set as follows:

1 For the government and the central bank 1 Taler for one point

2 For the union representative, 19,6875 Talers for one point

3 For the employer representative 50 Talers for one point

4 For the firms, 250 Talers for one point

Total points were then converted into EUROs by the following formula:

\begin{tabular}{|cc|}
\hline Total points $x$ between & Conversion into $€$ \\
\hline 0 and 60 & $\mathrm{x}$ \\
60 and 100 & $60+0.5(\mathrm{x}-60)$ \\
100 and 200 & $80+0.3(\mathrm{x}-100)$ \\
200 and 300 & $110+0.2(\mathrm{x}-200)$ \\
over 300 & $130+0.1(\mathrm{x}-300)$ \\
\hline
\end{tabular}

\section{REFERENCES}

[1] Reinhart CM, Rogoff KS. The modern history of exchange rate arrangements: a reinterpretation. Q J Econ 2004; 119(1): 1-48.

[2] ReinhartCM, Rogoff KS. Forthcoming.from financial crash to debt crisis. Am Econ Rev Available as NBER working paper 15795, March 2010.

[3] Rogoff KS. Why not a global currency?. Am Econ Rev 2001; 91(20): 243-7

[4] Pope R. Revaluation: help or hindrance to australian manufacturing? Centre for applied economic research paper 14: University of New South Wales of Sydney, Australia 1981.

[5] Pope R. Revaluations: help or hindrance to australian manufacturers?. In: Gossling WF, Ed. Western Pacific Trade, Suffolk: Input-Output Publishing Company 1985: pp. 75-104.

[6] Pope R. Revaluations: Help or Hindrance to australian manufacturing?.PhD [dissertation].Sydney, Australia: Department of Economics, University of New South Wales 1987.

[7] Pope R. A challenge to orthodoxy: appreciations and manufacturing output. Mimeo, Cambridge, USA: Massachusetts Institute of Technology 1992

[8] Rose A. The effect of common currencies on international trade: a meta-analysis. In: Alexander V, von Furstenberg GM, Mélitz J,
Eds. Monetary unions and hard pegs. Oxford: Oxford University Press 2004; pp. 101-11.

[9] Pope R. Data appendix. In: Western Pacific Trade. Gossling WF, Ed. Suffolk: Input-Output Publishing Company 1986: 175-82.

[10] Pope R, Selten R. Local manufacturing hurt by depreciations: a theoretical model reflecting the australian experience. Pac Econ Rev 2002; 7(3): 403-64.

[11] Sheets ND. Essays in intersectoral economics: exchange rates, public capital and productivity. PhD [dissertation]. Cambridge USA: Massachusetts Institute of Technology, Department of Economics 1993; Available from: http://hdl.handle.net/1721.1/127 08 .

[12] Obstfeld M, Rogoff KS. Foundations of international macroeconomics. Cambridge USA: MIT press 1997

[13] Davidson P, The keynes solution, the path to global prosperity. London, UK: Palgrave Macmillan 2009.

[14] Marglin SA. The dismal science: how thinking like an economist undermines community. Cambridge, USA: Harvard University Press 2009.

[15] Samuelson PA. Foundations of economic analysis.cambridge. USA: Harvard University Press 1947.

[16] Pope R. Beggar thy neighbour: exchange rate regime misadvice from misunderstandings of mundell (1961). World Economy 2009; 32 (2): 326-50. Available from: http://www3.interscience.wiley. com/journal/122205589/issue?CRETRY $=1 \&$ SRETRY $=0$

[17] Friedman M. The Case for Flexible Exchange Rates.In:Friedman M. Essays in Friedman M. Positive Economics. Chicago, USA University of Chicago Press 1953.

[18] Friedman M. The optimum quantity of money..In: Friedman M, Ed. The optimum quantity of money and other essays. Chicago, USA: Aldine Publishing 1969.

[19] Meade J. The theory of international economic policy. Vol. 1: The balance of payments. Vol. 2: Trade and welfare with mathematical supplements. London, UK: Oxford University Press 1951.

[20] Cobham D. The exchange rate as a source of disturbances: The UK 1979-2000, Natl I Econ Rev 2002; 181(1): 96-112.

[21] Bergo J. Cyclical developments, monetary policy and the krone exchange rate. Speech by Deputy Governor Jarle Bergo, Østfold University College, Sarpsborg, 28 September 2006.

[22] Meese R,Rogoff K. Empirical exchange rate models of the seventies: do they fit out of sample? J Int Econ 1983; 14: 3-24.

[23] Krugman P. Recent thinking about exchange rate determination and policy. In: Blundell-Wignall $\mathrm{A}$, Ed. The exchange rate, international trade and the balance of payments. Economic Group, Reserve Bank of Australia. Sydney, Australia: Ambassador 1993 : pp. 6-22.

[24] Pagan A. A perspective. In: Blundell-Wignall A, Ed. The exchange rate, international trade and the balance of payments, Economic Group, Reserve Bank of Australia. Sydney, Australia: Ambassador 1993: pp. 316-25.

[25] Chinn M, Cheung YW, Pascual AC. Empirical exchange rate models of the 1990's: are any fit to survive?. J Int Money Financ 2005; 24: 1150-75.

[26] Friedman D. Speculative Attacks: An Experiment. Presentation to the economics science association Tucson 2005

[27] Bissoondeeal RK, Binner JM, Elger T. Monetary models of exchange rates and sweep programs. App Financ Econ 2009; 19(14): 1117-29

[28] Engel C, Mark NC, West KD. Exchange rate models are not as bad as you think. NBER Working Paper No. 13318, August 2007.

[29] Putman B, Quintana J. Bayesian global portfolio management. Am Stat A, Section on Bayesian statistical science, 1993; Proceedings volume 110-17.

[30] Pagan A. Report to the court of directors of the bank of England on the modeling and forecasting systems within the bank 2005 .

[31] Fama EF. The behavior of stock-market prices. J Bus 1965; 38(1) 34-105.

[32] Burt J, KaenFR, Booth GG. Foreign exchange market efficiency under flexible exchange rates. J Financ 1977; 32 (4):1325-30.

[33] Wang PJ, Jones T. Testing for efficiency and rationality in foreign exchange markets - a review of the literature and research on foreign exchange market efficiency and rationality with comments. J Int Money Financ 2002; 21: 223-39.

[34] Rapp TA, Sharma SC. Exchange rate market efficiency: across and within countries. J Econ Bus 1999; 5: 15-34. 
[35] Frankel JA, Froot KA. Using survey data to test standard propositions regarding exchange rate expectations. Am Econ Rev 1987; 77(1): 133-53.

[36] Levich RM. Is the foreign exchange market efficient?. Ox Rev of Econ Policy 1989; 5(3): 40-60.

[37] Phelps E. Lessons from the corporatist crisis in some Asian nations. J Policy Modeling 1999; 21(2): 331-9.

[38] Barnett WA, He Y. Stability analysis of continuous-time macroeconomic systems. Stud Nonlin Dynam Economet 1999; 3(4): 169-88.

[39] Sordi S, Vercelli A. Financial fragility and economic fluctuations: numerical simulations and policy implications. Quaderni Del Dipatimento Di EconomiaPolitica, Siena, Ottobre 2003.

[40] Hendry DF, Mizon GE. On the Mathematical basis of intertemporal optimization, mimeo, Department of Economics, University of Oxford, UK August 2010.

[41] Merton RC. Comments on the reasons for long term capital management's problems. Presentation american economic association meetings, New Orleans 2001.

[42] Soros G. The alchemy of finance. New Jersey, USA: Wiley \& Sons 1987; p. 20.

[43] Osler C. Currency orders and exchange-rate dynamics: explaining the success of technical analysis. J Financ 2003; 58: 1791-819.

[44] Samuelson P. Probability, utility and the independence axiom. Econometrica 1952; 20: 670-8.

[45] Friedman M, Savage LJ. Utility analysis of choices involving risk. J Pol Econ 1948; 56(4): 279-304.

[46] Mundell R. A theory of optimum currency areas. Am Econ Rev 1961; 51: 657-65.

[47] Pope R. The pre-outcome period and the utility of gambling. In: StigumB, Wenstøp F, Eds. Foundations of utility and risk theory with applications. Dordrecht, Netherlands: D. Reidel 1983; pp. 137-77.

[48] Pope R. The riskless utility mapping of expected utility and all theories imposing the dominance principle: its inability to include loans, commitments, even with fully described decision trees. In: Schmidt U, Traub S. Eds. Advances in public economics: utility, choice \& welfare. Heidelberg, Berlin and New York: Springer 2005; pp. 289-327.

[49] Pope R. Outcome segments and risk effects excluded under expected utility theory's representation theorem. Bonn Econ Discus Paper 2006/7

[50] Pope R, Selten R. Risk in a simple temporal framework for expected utility theory and for skat, the stages of knowledge ahead theory. Risk Decis Anal 2010/2011; 2(1): 5-32.

[51] Pope R. Reconciliation with the Utility of Chance by Elaborated Outcomes Destroys the Axiomatic Basis of Expected Utility Theory. Theor Decis 2000; 49: 223-34.

[52] Walsh V. Rationality, allocation and reproduction. Oxford, UK: Clarendon Press 1996.

[53] Von Neumann J, Morgenstern O. Theory of games and economic behavior. Princeton, New Jersey, USA: Princeton University Press 1947; 1953 and 1980

[54] Pope R. Timing contradictions in von neumann and morgenstern's axioms and in savage's 'sure-thing' proof. Theor Decis 1985; 18: 229-61.

[55] Pope R, LeitnerJ, Leopold-Wildburger U. The knowledge ahead approach to risk: theory and experimental evidence. Heidelberg, Berlin and New York: Springer Lecture Notes 2006/7.

[56] Pope R, LeitnerJ, Leopold-Wildburger U. Expected utility versus changes in knowledge ahead. Eur J Operations Res 2009; 199 (3): 892-901.

[57] Savage LJ. The foundations of statistics. New York: Wiley 1954 and 1972 .

[58] Pope R. Delusion of certainty in savage's sure-thing principle. J Econ Psychol 1991; 12(2): 201-41.

[59] Papademos L. Policy-making in EMU: strategies, rules and discretion. Econ Theor 2006; 27: 25-38

[60] Cobham D. The overvaluation of sterling since 1996: How the policy makers respond and why. Econ J 2006; 116: F185-F207.

[61] Pope R, Selten R, KubeS, von Hagen J. Experimental evidence on the benefits of eliminating exchange rate uncertainties and why expected utility theory causes economists to miss them. Indian $\mathbf{J}$ Econ Bus 2008; 7(1): 1-31.
[62] Soros G. The new paradigm for financial markets: the credit crisis of 2008 and what it means. New York, US: Public Affairs 2008; $2^{\text {nd }}$ ed 2009

[63] Flandreau M, Ed. The money doctors: the experience of international financial advising 1850-2000. London and New York: Routledge 2003

[64] Hooks LM. The international lender of last resort: Europe in the nineteenth century. Working paper. Southern Economic Association 2000 .

[65] Butkiewicz, JL. Governor eugene meyer and the great contraction. Res Econ Hist 2008; 26: 273-307.

[66] Cooper R. Almost a century of central bank cooperation. In: Brio C, Toniolo G, Clement P, Eds. Past and future of central bank cooperation. UK: Cambridge University Press 2008.

[67] Mehrling P. Interview with Paul A. Volker' macroeconomic dynamics 2001; 5: $434-60$.

[68] Dominguez K, Frankel JA. Does foreign-exchange intervention matter? The Portfolio Effect.Am Econ Rev 1993; 83(5): 1356-69.

[69] Frankel JA. International capital flows and domestic economic policies. NBER Working 1988; Paper No. 2210.

[70] Frankel JA. Recent Exchange-Rate Experience and Proposals for Reform. Am Econ Rev Papers and Proc1996; 86 (2): 153-8

[71] Frankel JA, Bergsten CF, MussaM. Exchange rate policy. In: Feldstein M, Ed. American economic policy in the 1980s. Chicago, US: University of Chicago Press 1994.

[72] Zemin H. Keep reforming the rmb exchange rate system: reasons and direction, mimeo, east china normal university (ecnu) shanghai, translation by institute of world economy. Shanghai Academy of Social Sciences (SASS) 2007.

[73] Swan T. Economic control in a dependent economy with the earlier versions mimeographs distributed at his 1950s Australian National University seminar presentations of this material in 1952, 1953 supplied to the author by Trevor Swan and then later re-supplied to Robin Pope by Peter Swan, while the very similar paper appeared in Econ Rec 1960; 51-66.

[74] Davidson P. Interpreting keynes for the $21^{\text {st }}$ century. The collected writings of Paul Davidson, Palgrave, Great Britain vol 4: 2007.

[75] Barro R. The right choice for the fed: Bernanke, an expert on inflation targeting, is likely to keep a cool head in a crisis, Newsweek, November 7, 2005, http://www.businessweek.com/mag azine/content/05 45/b3958123.htm

[76] Dasgupta S, 2009, Clinton focusses on selling US treasury bills to China, The Times of India, February 21, http://timesofindia.indiat imes.com/news/business/international-business/Clinton-focusseson-selling-US-treasury-bills-to-China-/articleshow/4166921.cms

[77] Volcker P, Gyohten T. Changing fortunes, Times Books. New York, 1992.

[78] Rukstad MG. Paul volcker and the federal reserve 1979-82. Harv Bus Sch Rev 2003; 9-386-055: 1-30. Available at: www.nd.edu/ $\sim$ nmark/MonetarPolicy/Paul\%20Volker.pdf

[79] Mundell R. The international monetary system and the case for a world currency. Leon Kozminski Academy of Entrepreneurship and Management (WSPiZ) and TIGER Distinguished Lectures Series n. 12, Warsaw, 2003

[80] McKinnon RI. Exchange rates under the East Asian dollar standard: living with conflicted virtue. Cambridge, USA: MIT Press 2005

[81] Mundell R. In: Michael M, moderator. Four nobel laureates discuss global economic challenges 2002. Available from: http://www.dig italnpq.org/global_services/global_ec_viewpoint/9-16-02.html

[82] Mundell R. China should keep currency peg, China Daily, lecture organised by the Chinese University of Hong Kong, with speech published by the China Daily2005. Available at http://www. chinadaily.com.cn/english/doc/2005-06/03/content_448457.htm

[83] Alesina A, Wagner A. Choosing (and Reneging on) exchange rate regimes. J Eur Econ Assoc 2006; 4(4): 770-99

[84] Obstfeld M. International macroeconomics: beyond the mundellfleming model. Center for international and development economics research working Paper C01-121, 2001.

[85] Selten, R. Aspiration adaptation theory. J Math Psychol 1998; 42: 191-214.

[86] Kaiser J,Kube S. Currency speculation behaviour of industrial firms: evidence from a two-country laboratory experiment. J BehavFinanc 2009; 10(1): 44-54.

[87] Zellner A, Peck S. Simulation experiments with a quarterly macroeconometric model of the U.S. economy. In: Powell AA, 
Williams RA, Eds. Econometric studies of macro and monetary relations. Netherlands: North-Holland: 1973; pp. 149-68.

[88] Dixon PB, Parmenter BR, Powell AA, Vincent PD. The agricultural sector of Orani 79: theory, data, and application. In: Kelley AC, Sanderson WG, Williamson JG, Eds. Modeling growing economies in equilibrium and disequilibrium, proceedings of an iiasa meeting, November 1980. Durham USA: Duke University Press 1983; pp. 237-74.

[89] Pope R. Comment on Claus Konrad and Tobias Schmidt, cge models for environmental policy analysis: the gem-e3 model for the eu member states, paper presented to the workshop of empirical studies in environmental policy. Center for European Integration Studies, Bonn University, July 1997. In: Maxwell JW, von Hagen J, Eds. Empirical Studies of Environmental Policies in Europe.Netherlands: Kluwer 2000.

[90] Pope R, Pope D. Predictionists, assumptionists and relatives of the assumptionists. Aust Econ Papers 1972; 11: 224-8.

[91] Pope R, Selten R, Kube S, Kaiser J, von Hagen J. Exchange rate determination: a model of the decisive role of central bank cooperation and conflict. Bonn University Working Paper 2007.

[92] Tietz R. EinanspruchsanpassungsorientiertesWachstums-und-Konjuncturemodel (KRESGO) (An aspiration-adaptation oriented growth and cyclical model) BeiträgezurexperimentellenWirtschaftsfors chung (Contributions to experimental economics), 4.Tübingen: J.C.B. Mohr (Paul Siebeck) 1973.

[93] Becker O, Selten R. Experiences with the management game SINTO - Market. In: Sauermann H, Ed. Beiträgezure xperimentel len Wirtschaftsforschung (Contributions to experimental economics), 2. Tübingen: J.C.B. Mohr (Paul Siebeck):1970; pp. 136-50. This is further explored in: Becker O, FeitT, Hofer, V, Leopold-Wildburger U, Pope R, Selten R. Männerschöpfen Märktebesseraus - $\quad$ EmpirischeEvidenzanhand des Unternehmensplanspiels SINTO-Markt (Men create better markets - empirical evidence of enterprise planning from playing the sinto business game. Perspektivender Wirtschafts Politik (Persp Polit Econ) 2006; 7(4): 445-58.

[94] Dörner D, Kreuzig HW, ReitherF, Stäudel T, Eds. Lohhausen. VomUmgangmitUnbestimmtheit und Komplexität [Lohhausen. on dealing with uncertainty and complexity]. Bern, Switzerland: Hans Huber 1983.

[95] MacKinnon AJ, Wearing AJ. decision making in dynamic environments. In: Stigum B, Wenstøp F, Eds. Foundations of utility and risk theory with applications. Dordrecht: D. Reidel 1983; pp. 399-422.

[96] Cobham D. Ed. European monetary upheavals. New York: Manchester University Press 1994.

[97] Cobham D. The making of monetary policy in the UK 1975-2000. London: Wiley 2002.

[98] Cobham D. The overvaluation of sterling since 1996: How the policy makers respond and why. Econ J 2006; 116: F185-F207.

[99] Stiglitz J Globalisation and its Discontents. New York: Norton 2002.

[100] Fleisig H. Long-term capital flows and the great depression: the role of the United States, 1927-1933. J Financ 1971; 26(3): 794-5.

[101] Claessens S, Dooley MP, Warner A. Portfolio capital flows: hot or cold?. World Bank Rev 1995; 9(1): 153-74.

[102] Singh A. Capital account liberalization, free long-term capital flows, financial crises and economic development. mimeo, Queens' College, University of Cambridge 2002.

[103] Borch JH. A Note on Uncertainty and Indifference Curves. Rev Econ Stud 1969; 36(1): 1-4.

[104] Feldstein MS. Mean-variance analysis in the theory of liquidity preference and portfolio selection. Rev Econ Stud 1969; 36: 5-12.

[105] Schneeweiß H. EntscheidungskriterienbeiRisiko (Decision criteria under risk). Berlin: Springer 1967.

[106] Schneeweiß H. Die Unvertäglichkeit von (m, s))-prinzip und Dominanz-prinzip' (The incompatibility of the mean-variance principle and the dominance principle), Unternehmensforschung (Operations research) 1968; 12: 180-4.

[107] Schneeweiß H. Note on two dominance principles in decision theory, Unternehmensforschung (Operations research) 1968; 12: 213-6.

[108] Schneeweiß H. The $(\mathrm{m}, \mathrm{s}))$ decision criterion on the class of normal distributions. Inference Decis 1973; 1: 23-30.

[109] Schneeweiß H. On the consistency of classical decision criteria. Inference Decis 1973; 1:31-44.
[110] Pope D. Bank deregulation yesterday and today: lessons of history. In: Snooks GD, Ed. Historical analysis in economics. London: Routledge, 1993; pp. 171-200. Earlier appeared in Australian National University working papers in economic history No. 156. 1991.

[111] United Nations conference on trade and development's trade and development report. USA 2010.

[112] Alesina A, Barro R. Dollarisation. Am Econ Rev 2001; 91(2): Papers and Proceedings May: 381-5.

[113] Courchene T, Harris RC. Canada and a North American monetary union. Can Bus Econ 1999.

[114] Courchene T. Alternative North American currency arrangements: a research agenda. Policy/ Analyse de politique1999; 25 (3): 30814.

[115] Grubel H. The case for the Amero: the economics and politics of a North American monetary union. Vancouver: Fraser Institute 1999.

[116] Cooper R. A monetary system for the future. Foreign Affairs 1984; 63(1): 166-84.

[117] Bonpasse M. The single global currency: common cents for the world 2006. Available from: http://www.singleglobalcurrency.org/ documents/TheSingleGlobalCurrencyCommonCentsforCommercef orIRBCDubai.pdf

[118] Teichrib C. one world, one money: looking to a global currency: forcing change. http://www.freerepublic.com/focus/f-news/19554 $23 /$ posts

[119] The Economist. One world, one money. 1998; 349(8087): 80.

[120] Pronina L. medvedev shows off sample coin of new 'World Currency' at G-8, July 10, 2009. Available from: http://www.bloomberg.com/apps/news?pid=newsarchive \&sid=aeF VNYQpByU4

[121] International Monetary fund strategy, policy and review department, reserve accumulation and international monetary stability. USA 2010.

[122] Media Resources.Wrapup 3-Russia, China to push global currency at G8 summit, July 7, 2009. Available from: http://www.re uters.com/article/usDollarRpt/idUSL74154220090707

[123] Marquit M. Geithner and his world currency, SDRs and more, right side news 2009. Available from: http://www.rightsidenews.com/ 200904084323/editorial/geithner-and-his-world-currency-sdrs-andmore.html

[124] EichengreenB. solving the currency conundrum. Econ Notes 2000; 29(3): 315-40.

[125] Arestis P, Basu S, Mallick S. Financial globalization: the need for a single currency and a global central bank. J Post Keynesian Econ 2005; 27(3): 507-31.

[126] Svensson LEO.Price stability as a target for monetary policy: defining and maintaining price stability. CEPR Discussion Papers 2196, C.E.P.R. Discussion Papers 1999

[127] Carew E. Fast Money 2.Sydney, Australia: Allen and Unwin 1985.

[128] Pope R. How has the policy of a floating exchange rate altered macroeconomic policy options? Case study for post-graduate public policy programme, Australian National University, Canberra 1986.

[129] Taylor JB. The role of the exchange rate in monetary-policy rules. Am Econ Rev papers and proceedings 2001; 91(2): 263-7.

[130] Cross SY. Notes for FOMC. 1990.

[131] Svensson L Escaping from a liquidity trap and deflation: the foolproof way and others. J Econ Perspect 2003; 17(4): 145-66.

[132] Kilponen J, Leitemo K. Discretion and the transmission lags of monetary policy. Bank of Norway, Working Paper 2007.

[133] Pianolto S quoted in Steve Robrahn, Fed's Pianalto sees slow rebound; inflation in focus. 2009; Available from: http://www.reute rs.com /article/businessNews

[134] Mishkin F. In praise of an explicit number for inflation. Financial Times 2009.

[135] Hausken K, Pluemper T. Containing contagious financial crises: the political economy of joint intervention into the asian crisis Public Choice 2002; 111(3-4): 209-36.

[136] Ramiakrishnan U, Zalduendo J. The role of IMF support in crisis prevention. IMF Working Paper 2006.

[137] Dooroodian K, Caporale T. Central bank intervention and foreign exchange volatility. Int Adv Econ Res 2006; 385-92.

[138] Freedman C, Ötker-Robe R. Country experiences with the introduction and implementation of inflation targeting. IMF Working Paper 2009, WP/09/161, planned to be Chapter 10 in the monograph Charles Freedman, Douglas Laxton and İnciÖtker- 
Robe eds, On Implementing Full-Fledged Inflation-Targeting Regimes: Saying What You Do and Doing What You Say, slated for publication 2009 by IMF bookstore http://www.imf.org/ external/pubs/ft/wp/2009/wp09161.pdf

[139] Telser L. Securing the means of payment: the ultimate requisite of a modern economy. Economist's Voice 2008; 5(3): Article 7. Available at: www.bepress.com/ev/vol5/iss3/art7/

[140] Telser L. The fed's real job. The Economists' Voice 2007; 4(4): article 4. Available at: http://www.bepress.com/ev/vol4/iss4/art4

[141] Telser L. Solvency vs competition: hobson's choice for the fed. J Int Money Financ 2007; 26: 1151-73.

[142] US pubic broadcasting system.paul volcker interview. Available at: http://www.pbs.org/fmc/interviews/volcker.htm

[143] Williamson J, Ed. Estimating equilibrium exchange rates. Peterson institute for international economics 1994.

[144] Calvo GA, Reinhart CM. Fear of floating. Q J Econ 2002; 379-408.

[145] Calvo GA. The case for hard pegs in the brave new world of global finance. Presented at the ABCDE Europe Paris, June 26 2000; Available from: http://www.eclac.cl/ilpes/noticias/paginas/1/22911/ Calvo2000.pdf

[146] Wyplosz C.European monetary union: the dark sides of a major success. Econ policy 2006; 21(46): 209-61.

[147] Eichengreen B. Can emerging markets float? should they inflation target. Paper presented to the Central Bank of Brazil and in an earlier form to the Bank of England 2001.

[148] Polanski Z. Poland's experience with inflation targetting.bank of england presentation. Available at: http://www.tcmb.gov.tr/yeni/ evds/yayin/kitaplar/enf_kitap/5-Zbigniev_Polanski.pdf

[149] Barro R, Lee JW, IMF Programs. Who is chosen and what are the effects?. J Monet Econ 2005; 52: 1245-69.

[150] Von Hagen J, Zhou J. The choice of exchange rate regime in developing countries: a multinomial panel analysis. J Int Mon Financ 2007; 26(7): 1071-94.

[151] Allais M. Forgetfulness and interest..J Money Credit Bank 1972; 4: 40-73.

[152] Blatt JM. Dynamic economic systems. a post-keynesian approach brighton. Sussex: Wheatsheaf Books 1983.

[153] Thorbecke W. How would an appreciation of the renminbi affect the u.s. trade deficit with china?. BE J Macroeconom Top 2006; 6(3): Article 3.

[154] Marschak J. Rational Behavior, Uncertain Prospects, and Measurable Utility. Econometrica 1950; 18(2): 111-41.

[155] Markowitz HM. Portfolio selection: efficient diversification of investments. $1^{\text {st }}$ ed. New York: Wiley 1959; $2^{\text {nd }}$ ed New Haven: Yale University Press 1970, $3^{\text {rd }}$ ed. Oxford: Basil Blackwell 1991.

[156] Caplin A, Leahy J. Psychological expected utility theory and anticipatory feelings. Q J Econ 2001; 116: 55-79
[157] Kreps DM, Porteus EL. Temporal Resolution of Uncertainty and Dynamic Choice Theory. Econometrica 1978; 46(1): 185-200.

[158] Klibanoff P, Ozdenoren E. Subjective recursive expected utility. Econ Theor 2007; 30(1): 49-87.

[159] Rose A. Why have currency unions dissolved? A test of optimum currency area theory. Vox 2008

[160] Pope R. Evidence of deliberate violations of dominance due to secondary satisfactions - attractions to chance. Homo Economicus 2001; 14(2): 47-76.

[161] Pope R. Biasses from omitted risk effects in standard gamble utilities. J Health Econ 2004; 25: 695-735.

[162] Eichengreen B, Wyplosz C, Branson WH, Dornbusch R. The unstable EMS. Brookings Pap Econ Act 1993; 1: 51-143.

[163] Mélitz J. French monetary policy and recent speculative attacks on the franc. In: Cobham D, Ed. European Monetary Upheavals. New York: Manchester University Press 1994; pp. 61-77.

[164] Cobham D, Papadopoulos A, Zis G. The cost of political intervention in monetary policy. University of St. Andrews, Department of Economics Discussion Paper Series 2001 No. 0114.

[165] Simon HA. A behavioral model of rational choice. Q J Econ 1955; 69: 99-118.

[166] Sauermann H, Selten R. Anspruchsanpassungs theorieder unternehmung (Aspiration-adaptation theory for the Firm), Zeitschriftfür die gesamteStaatswissenschaft. J Gen Polit Econ 1962; 118: 577-97.

[167] Janis IL, Mann L. Decision Making: A psychological analysis of conflict, choice, and commitment. New York: Free Press, 1977.

[168] Cyert R, March J. The behavioral theory of the firm. USA: Prentice 1963.

[169] Huber O. EntscheidenalsProblemlösen (The decision process as problem solving). Bern: Huber 1982.

[170] Montgomery H, Svenson O. A think aloud study of dominance structuring in decision processes. In: Tietz R, Ed. Aspiration levels in bargaining and economic decision making. Berlin: Springer 1983; pp. 366-83.

[171] Brandstaetter H, Gigerenzer G, Hertwig R. The priority heuristic: making choices without trade-offs. Psychol Rev 2006; 113: 409-32.

[172] Keynes JM. The General theory of employment interest and money. New York: Harcourt, Brace 1936

[173] Bell D. Components of risk aversion. In: Brans J, Ed. Operational research '81. Amsterdam: North Holland 1981; pp. 235-42.

[174] Hagen O. Rules of Behaviour and expected utility theory. Compatibility versus dependence. Theor Decis $1985 ; 18: 31-45$.

[175] Beine M, Lecourt C. Communication and transparency in exchange rate policy. European Central Bank Communication Workshop, Zurich 2006. Available at: http://www.kof.ch/chair/workshops/ ecb/lecourtpres.pdf 